\title{
DEPARTMENT OF ECONOMICS AND FINANCE
}

SCHOOL OF BUSINESS AND ECONOMICS

\author{
UNIVERSITY OF CANTERBURY \\ CHRISTCHURCH, NEW ZEALAND
}

Mean Reversion in Asia-Pacific Stock Prices:

New Evidence from Quantile Unit Root Tests

Gilbert V. Nartea

Harold Glenn A. Valera

Maria Luisa G. Valera

\section{WORKING PAPER}

No. $16 / 2019$

Department of Economics and Finance

School of Business

University of Canterbury

Private Bag 4800, Christchurch

New Zealand 


\title{
WORKING PAPER No. 16/2019
}

\section{Mean Reversion in Asia-Pacific Stock Prices: New Evidence from Quantile Unit Root Tests}

\author{
Gilbert V. Nartea ${ }^{1 \dagger}$ \\ Harold Glenn A. Valera ${ }^{2}$ \\ Maria Luisa G. Valera ${ }^{3}$
}

November 2019

\begin{abstract}
We investigate the stationarity of real stock prices among 12 Asia-Pacific countries over the period 1991-2018. The methodology employed is driven by the need to address three key concerns: (i) the identification of which positive or negative shocks are linked to stationarity; (ii) the identification of different speeds of adjustment towards long-run equilibrium; and (iii) the identification of mean reversion and potential asymmetric speed of adjustment before and after the 2008-2009 global financial crisis. To meet these concerns, we examine the time series properties of the data within a quantile unit root testing framework. Our results generally indicate that real stock prices are stationary at the upper quantiles only. There is also evidence of a varied speed of adjustment process across the quantiles where stationarity is present. Further analysis indicates that real stock prices became much more reverting and with a faster speed of adjustment after the global financial crisis, except for Japan and New Zealand.
\end{abstract}

Keywords: Stock prices, Mean reversion, Quantile unit root regression

JEL Classifications: C1, C5, G1

${ }^{1}$ Department of Economics and Finance, University of Canterbury, NEW ZEALAND

${ }^{2}$ Agri-Food Policy Platform, International Rice Research Institute, PHILIPPINES

${ }^{3}$ Department of Economics, University of the Philippines Los Banos, PHILIPPINES

†Corresponding author: Gilbert Nartea, email: gilbert.nartea@canterbury.ac.nz 


\section{Introduction}

Do stock market prices follow a random walk or a mean-reverting process? This basic question, posed by Fama (1970) nearly 50 year ago, and since labeled as the Efficient Market Hypothesis or EMH, remains at the core of a continuing debate among economists and finance researchers. The EMH states that a market is efficient if prices at any point in time always fully reflect all available information. The weak-form efficiency variant of the EMH which presumes that future returns cannot be predicted based on past information is the most frequently examined in the literature. From an empirical perspective, the basic question posed by the EMH is one that, at least in principle, should be relatively easy to answer. Yet the EMH continues to receive considerable attention (see, for example, Narayan and Smyth (2005), Lean and Smyth (2007), Lim et al. (2008), Lee et al. (2010), Lee et al. (2014), Shen and Holmes (2014a), Wang et al. (2015), among others).

There are at least two reasons for continued interest in the EMH. First, as suggested by Bose (2005), the implications of the close link between the stock market and the real economy are fundamentally important in formulating economic policies. Mauro (2003, p. 131), writing in the context of emerging economies, made this point concisely: "Given the speed with which stock market prices become available, it seems that the stock market could be a helpful leading indicator in forecasting economic growth. Moreover, if one were to find that stock price changes that are not justified by fundamentals do really affect output, this would raise a number of policy issues that would be particularly relevant for emerging markets.”

Another reason for the sustained interest in this topic is that the fundamental question suggested by the EMH is naturally an empirical one; it is simply impossible to answer at some point without turning to data. Perhaps not surprisingly, it seems the answer to the empirical question posed by the EMH hinges on appropriate specification of the dynamic behavior of stock prices. Empirical work on this topic argued that the behavior of stock prices is driven by 
nonlinearities that can be attributed to institutional constraints, market frictions and transaction costs. Relevant examples include Lim and Liew (2007), Chen and Kim (2011), Lee at al. (2014), and Shen and Holmes (2014b), though the evidence is still mixed at best. Tests for mean reversion of stock prices typically boiled down to an examination of the sign and significance of the estimated autoregression coefficient, depending on whether large negative shocks have potentially different impacts from large positive shocks. Of course many researchers recognized that the presence of structural breaks might also explain the nonlinearity of stock prices (Narayan et al. 2013; Shen and Holmes, 2014a). Early work on this research area tended to support the conjecture that structural breaks based on financial crisis and other critical economic events lead to regime shifts in stock price dynamics.

While considerable progress has been made in examining the mean reversion of stock prices, there is scope for additional work. Research on this topic has yet to consider the question of whether stationarity of stock prices is associated with positive or negative shocks. Previous research has considered only the case of the constant speed of stock price adjustment towards its equilibrium with a conditional mean function. A more complete analysis would examine mean reversion of stock prices that accounts for potential asymmetry and different speed of adjustment towards long-run equilibrium for various signs and sizes of shocks affecting stock prices.

Additionally, the 2008-2009 global financial crisis, GFC henceforth, has renewed the concern about stock market inefficiency in emerging market economies. As noted by Lim and Brooks (2011), stock market inefficiency could arise due to the existence of a financial crisis because investors generally panic during this critical economic event, adversely affecting their ability to price stocks efficiently. There is still a dearth of research on the impact of the GFC on the mean reversion of stock prices. Among a very few studies, Anagnotidis et al. (2016) have considered explicitly the effect of the GFC on the efficiency of Eurozone stock markets. They 
did so by using the Generalized Hurst Exponent method and found significant mean reversion of stock prices in 12 Eurozone countries. Moreover, applying a Markov regime-switching unit root test for 12 Asia-Pacific countries, Shen and Holmes (2014a) found that the aftermath of the GFC is more likely associated with a much faster speed of adjustment of real stock prices towards a long-run equilibrium. Although they showed that real stock prices are mean-reverting in both stationary and non-stationary regimes, their approach is restricted to a certain number of regimes. Therefore, further testing of stock price mean reversion that accounts for the possibility that shocks of different sign and magnitude have different impact on stock prices is called for.

This paper attempts to fill these gaps by examining the different behavior of real stock prices for 12 Asia-Pacific countries in a quantile unit root testing framework. An investigation of the dynamic behavior of real stock prices using this sample of countries is worthwhile because their economic importance in the region has increased substantially in recent years. The contribution of this paper is twofold. First, it suggests an alternative method to test for mean reversion of real stock prices. In contrast to the related literature, in which the specific number of regimes is restricted, this paper incorporates the differences in the transmission of all kinds of different shocks using an adaptation of the quantile unit root testing proposed by Koenker and Xiao (2004). The test is conducted in order to verify if mean reversion is affected by the nature of shocks hitting real stock prices. That is, we aim to verify if there is asymmetric speed of adjustment towards long-run equilibrium for positive or negative shocks. The quantile unit root test allows us to examine the effect of shocks of different signs and magnitudes on real stock prices. This is in contrast to the conventional unit root tests, which provides only a single test statistic capturing the constant speed of adjustment with a conditional mean function (see, for example, Tsong and Lee, 2011). Moreover, the quantile unit root test reduces estimation 
uncertainty by avoiding the estimation of additional regime parameters (Hosseinkouchack and Wolters, 2013).

The second contribution is that the examination of stationarity of real stock prices before and after the GFC adds to the literature on stock price behavior around periods of market turmoil especially during the recovery phase. As noted by Anagnostidis et. al. (2016), taking into account the impact of the GFC and its aftermath provides a suitable framework for investigating stock market efficiency. This is of potential interest to policy makers because the stabilization of financial policies could be different before and after the GFC. If exogenous shocks to stock prices are temporary, particularly during the crisis, then the stabilization of financial policies will not have permanent effects (Lee et al., 2014). In addition, a further elaboration on the link between the dynamic behavior of stock prices and the GFC would help investors predict future movements in stock prices more accurately.

The rest of the paper is organized as follows: Section 2 provides a discussion of the most recent studies of stock price mean reversion; Section 3 discusses the quantile unit root test that we employ and the data; Section 4 discusses the empirical results and Section 5 presents the conclusions and policy implications.

\section{Literature review}

The dynamic behavior of stock prices has been the subject of a burgeoning literature. One variant of this literature provides explanations for mean reversion in stock prices. These include, among others, the stock market overreaction hypothesis (De Bondt and Thaler, 1985; Shefrin and Statman, 1985), which states that stock prices have temporary swings away from their fundamental value due to optimism and pessimism; irrational behavior of noise traders (Poterba and Summers, 1988); and stock market size and associated risk factors (Zarowin, 1990; Richards, 1997). Summers (1986) emphasized that the mean reversion in stock prices can be 
observed if the expected returns are mean-reverting (Wang et al., 2015). This is because expected return is a function of the stock value under the assumption that all available information is incorporated into stock prices, which suggests that mean reversion does not necessarily contradict market efficiency (Fama and French, 1988). Conrad and Kaul (1993) explain that price-related microstructure-induced biases affect the specification of expected returns of low-priced stocks. Moreover, Chan (1988) and Ball and Kothari (1989) argue that variation in relative risk leads to negative serial correlation in relative returns which has a direct impact on expected relative returns.

Most of the studies of the weak-form EHM concerning Asia-Pacific countries have employed methodologies based on different unit root tests to investigate stationarity of stock prices. Some examples of studies that have utilized linear univariate unit root tests include Chaudhuri and Wu (2003), Groenewold et al. (2003), Narayan and Symth (2004), Phengpis (2006), Narayan and Symth (2007) and Setianto and Mannap (2011). On the other hand nonlinear univariate unit root tests are employed in Lim and Liew (2007), Qian et al. (2008), Munir and Mansur (2009), Tan et al. (2010), Chen and Kim (2011), Mishra and Mishra (2011), Gozbasi et al. (2014), Rizvi and Arshad (2016). However, the univariate unit root tests are criticized due to low power. To address this issue, some studies used panel-type unit root tests, including Narayan and Symth (2005, 2007, 2008), Ahmad et al. (2010), Lee et al. (2010), Shen and Holmes (2014b) and Lee et al. (2014). Other approaches have addressed structural breaks using panel data such as Lee et al. (2010), Lu et al. (2010), Shen and Holmes (2014b) and Lee et al. (2014), and using time-series data such as Chaudhuri and Wu (2004), Mishra et al. (2015) and Wang et al. (2015). Irrespective of which tests are considered, the results are mixed as to whether or not stock prices are stationary.

A few studies exist on the effect of financial crises on stock market efficiency. Some examples of empirical investigations that focused on the impact of the 1997 Asian Financial 
crisis include Hoque et al. (2007), Lim et al. (2008) and Kim and Shamsuddin (2008). In terms of the impact of the GFC, however, previous studies have focused on European Union stock markets. Examples of these studies include Horta et al. (2014), Smith (2012), Katris and Daskalaki (2013), Sensoy and Tabak (2015) and Anagnotidis et al. (2016).

Shen and Holmes (2014a) examine on the impact of the GFC on the mean reversion of stock prices for a sample of 12 Asia-Pacific countries using the Markov switching-regime approach and find that the GFC is associated with a shift in regimes with a faster speed of mean reversion. They argue that a single test statistic based on the single-regime ADF test covering the entire study period is inadequate in explaining the differences in the behavior of stock prices before and after the GFC. This has implications both for model-building and for statistical testing. In contrast to Shen and Holmes (2014a), the present study allows for the presence of transmission of all kinds of different shocks. In the search for weak-form EMH that does not restrict the analysis to a specific number of regimes, the most fruitful approach has been one where allowance is made for the possibility that shocks of different signs and magnitudes have different impacts on the behavior of real stock prices.

This is the first study that examines the behavior of stock prices in the Asia-Pacific region within a quantile unit root testing framework. In contrast to the above studies of asymmetries and nonlinearities, the methodology employed here enables us to not only test the null of non-stationarity across quantiles, but also to compare and contrast speeds of adjustment of stock prices towards to its long-run equilibrium level across quantiles. In addition to this, such an approach allows the measurement of local persistence and distinguishes globally between nonstationarity and mean reversion. Existing studies of Asia-Pacific stock price behavior only identifies a stationary (nonstationary) process in a specific number of regimes, which ignores valuable insights into quantile-varying behavior of stock prices. 


\section{Methods and data}

\subsection{Quantile unit root test}

This section outlines the quantile unit root testing method that is used for our empirical work. The test, developed by Koenker and Xiao (2004), has improved power because the potential heavy-tailed behavior in the data and magnitudes of shocks that are endogenously determined by the data are incorporated into the testing framework.

The conventional approach to assess the unit root properties of real stock prices is the ADF regression model with $q$ lags. Let $s_{t}$ denote the natural logs of the monthly real stock prices for a given country $i$ and $\varepsilon_{t}$ denote a white noise residual. The ADF regression of log real stock prices with a drift $\rho_{0}$ can be performed via the OLS estimation of

$$
\Delta s_{t}=\rho_{0}+\rho_{1} s_{t-1}+\sum_{i=1}^{q} \gamma_{i} \Delta s_{t-i}+\varepsilon_{t}
$$

where $\rho_{1}$ is the autoregression (AR) coefficient. The real stock price process contains a unit root, and hence nonstationary if $\rho_{1}=0$. The condition for stationary properties of real stock prices and for ruling out explosive behavior is where $-2<\rho_{1}<0$. Following Koenker and Xiao (2004), we define the $\tau$ th conditional quantile of $\Delta s_{t}$ as:

$$
\mathrm{Q}_{\Delta s_{t}}\left(\tau \mid \Gamma_{t-1}\right)=\rho_{0}(\tau)+\rho_{1}(\tau) s_{t-1}+\sum_{i=1}^{q} \gamma_{i}(\tau) \Delta s_{t-i}+\varepsilon_{t}
$$

where $\mathrm{Q}_{\Delta s_{t}}\left(\tau \mid \Gamma_{t-1}\right)$ is $\tau$ th quantile of $\Delta s_{t}$ conditional on the past information set, $\Gamma_{t-1}$. In Equation (2), the $\tau$ th conditional quantile of $\Delta \pi_{t}$ is denoted by $\rho_{0}(\tau)$, which measures the average size of shock hitting real stock prices in each quantile (Tsong and Lee, 2011). $\rho_{1}(\tau)$ measures the speed of mean reversion of $\Delta \pi_{t}$ within each quantile. The estimates for $\rho_{1}(\tau)$ can be used in approximating the half-lives (HL) for any monotonic stationary real stock price process in each quantile through the formula $\mathrm{HL}=\ln (0.5) / \ln \left(\hat{\rho}_{1}(\tau)+1\right)$. The HL can be 
approximated when the null hypothesis of $\rho_{1}(\tau)=0$ is rejected; otherwise, half-lives are set to be infinite. The optimal lag length is chosen according to the Akaike Information Criteria (AIC).

The coefficients $\rho_{0}(\tau), \rho_{1}(\tau)$ and $\gamma_{i}(\tau)$ are estimated by minimizing the sum of asymmetrically weighted absolute deviations:

$$
\begin{aligned}
& \min \sum_{t=1}^{n}\left(\tau-I\left(s_{t}<\rho_{0}(\tau)+\rho_{1}(\tau) s_{t-1}+\sum_{i=1}^{q} \gamma_{i}(\tau) \Delta \pi_{t-i}\right)\right)\left|s_{t}-\rho_{0}(\tau)+\rho_{1}(\tau) s_{t-1}+\sum_{i=1}^{q} \gamma_{i}(\tau) \Delta s_{t-i}\right| \\
& \text { where } I=1 \text { if } \quad s_{t}<\left(\rho_{0}(\tau)+\rho_{1}(\tau) s_{t-1}+\sum_{i=1}^{q} \gamma_{i}(\tau) \Delta s_{t-i}\right) \text { and } I=0 \text {, otherwise. }
\end{aligned}
$$

Given the solution for $\hat{\rho}(\tau)$ from Equation (3), the stochastic properties of $\Delta s_{t}$ within the $\tau$ th quantile can be tested using the $t$-ratio statistic proposed by Koenker and Xiao (2004) as follows:

$$
t_{n}(\tau)=\frac{f\left(\widehat{F^{-1}(\tau)}\right)}{\sqrt{\tau(1-\tau)}}\left(s_{-1}^{\prime} M_{Z} S_{-1}\right)^{1 / 2}(\hat{\rho}(\tau)-1)
$$

where $S_{-1}$ is the vector of lagged real stock prices and $M_{Z}$ is the projection matrix onto the space orthogonal to $Z=\left(1, \Delta s_{t-1}, \ldots, \Delta s_{t-q}\right)$. The consistent estimator of $f\left(F^{-}(\tau)\right)$ is $f\left(\widehat{F^{-1}(\tau)}\right)$, with $f$ and $F$ denoting the probability and cumulative density functions of $\varepsilon_{t}$ in Equation (2). To estimate $f\left(F^{-1}(\tau)\right)$, Koenker and Xiao (2004) proposed the following rule:

$$
f\left(\widehat{F^{-1}(\tau)}\right)=\frac{\left(\tau_{i}-\tau_{i-1}\right)}{x^{\prime}\left(\hat{\rho}\left(\tau_{i}\right)-\hat{\rho}\left(\tau_{i-1}\right)\right)}
$$

with $\tau_{i} \in \Gamma$. As shown in the empirical analysis below, we select $\Gamma=\{0.1,0.2, \ldots, 0.9\}$. The use of $t_{n}(\tau)$ statistic allows us to test the unit root hypothesis in each quantile. To be specific, this allows us to examine both the dynamics of real stock prices and the possibility of different mean reverting behavior when the series is hit by various sizes and signs of shock across a range of quantiles. The ADF and other unit root tests that only concentrate on the conditional central tendency of the series behavior do not permit an elaboration of such behavior. 
To obtain a more complete inference of the unit root behavior across quantiles, Koenker and Xiao (2004) proposed the quantile Kolmogorov-Smirnov (QKS) test as follows:

$$
\mathrm{QKS}=\sup \left|t_{n}(\tau)\right|
$$

We construct the QKS statistics by taking the maximum $\left|t_{n}(\tau)\right|$ statistics at $\tau_{i} \in \Gamma$. The QKS test provides a general perspective of the behavior of real stock prices and insights into global persistence. For example, if the shocks to real stock prices are short and long-lived in small and large quantiles, respectively, the QKS test means that the stationary behavior of the series in the low quantiles facilitates the whole process to revert to the series' steady-state level. The QKS test also indicates that real stock prices might change for a short period of time at various sizes of shocks that hit the series but unlikely to deviate from its steady-state level even when a positive shock such as a financial boom increases real stock prices.

Note that the limiting distributions of $t_{n}(\tau)$ and QKS test statistics are non-standard. In this study, the resampling procedure recommended by Koenker and Xiao (2004) is used to approximate the small-sample distributions of $t_{n}(\tau)$ and the QKS tests even though their limiting distributions are nonstandard. Following Koenker and Xiao (2004), this resampling procedure is outlined below:

1. Regress the $q$-order autoregression $\Delta s_{t}=\sum_{i=1}^{q} \hat{\gamma}_{i} \Delta s_{t-i}+\hat{\varepsilon}_{t}$ by ordinary least squares (OLS) and obtain estimates $\hat{\gamma}_{i}$ for $i=1,2, \ldots, q$, and the residuals $\hat{\varepsilon}_{t}$.

2. Draw a bootstrap sample of $\varepsilon_{t}^{*}$ with replacement from the empirical distribution of the centered residuals $\bar{\varepsilon}_{t}=\hat{\varepsilon}_{t}-(n-q)^{-1} \sum_{t=q+1}^{n} \hat{\varepsilon}_{t}$.

3. Generate the bootstrap sample of $\Delta s_{t}^{*}$ recursively using the fitted autorgression $\Delta s_{t}^{*}=$ $\sum_{i=1}^{q} \hat{\gamma}_{i} \Delta s_{t-i}^{*}+\hat{\varepsilon}_{t}^{*}$, with $\hat{\gamma}$ denoting the OLS estimates in step (1), and starting values $\Delta s_{i}^{*}=$ $\Delta s_{i}$ for $i=1,2, \ldots, q$.

4. Obtain the bootstrap sample of $s_{t}^{*}$ based on $s_{t}^{*}=s_{t-1}^{*}+\Delta s_{t}^{*}$ with $s_{1}^{*}=s_{1}$. 
5. With the resample $s_{t}^{*}$, compute the bootstrap counterparts of $\hat{\rho}_{0}(\tau), \hat{\rho}_{1}(\tau)$, the $t_{n}(\tau)$ and the QKS test, denoted by $\hat{\rho}_{0}^{*}(\tau), \hat{\rho}_{1}^{*}(\tau), t_{n}^{*}(\tau)$ and QKS*, respectively.

6. Repeat Steps 2 to 5 with 5000 bootstrap replications in this study.

7. Calculate the empirical distribution function of the 5000 bootstrap values of $\hat{\rho}_{0}^{*}(\tau), \hat{\rho}_{1}^{*}(\tau)$, $t_{n}^{*}(\tau)$ and $\mathrm{QKS}^{*}$ tests, and use these empirical distribution functions as an approximation of the cumulative distribution of the respective tests under the null.

8. Using the bootstrap $p$-value to make inference.

\subsection{Data}

We use monthly data on the natural logarithm of real stock price expressed in local currencies with the base year $2010=100$ for each of the 12 Asia-Pacific countries. The data are obtained from the International Financial Statistics. Noting that different results can be obtained using different indices, we use the market value-weighted index, consistent with the existing literature. In this study, we are interested in testing for a mean reversion model based on a long sample period consistent with the suggestion of Akarim and Sevim (2013). Hence, we focus on the time-span of the data instead of frequency and use monthly data over the period 1991:M1 to 2018:M8. Figure 1 plots real stock prices for each country in our sample which include Australia, China, Hong Kong, Indonesia, Japan, Malaysia, New Zealand, the Philippines, Singapore, South Korea, Taiwan and Thailand. The series exhibit mixed trends though it also shows that real stock prices noticeably declined during the 2008-2009 period which includes the global financial crisis.

\section{INSERT FIGURE 1 HERE}

Table 1 presents the mean, standard deviation, skewness, kurtosis, and Jarque-Bera (JB) normality test statistic for monthly real stock prices. Thailand and Malaysia have respectively 
the most and least variability based on sample standard deviations. It is noticeable that the JB test rejects the null hypothesis of normality with very low $p$-values for all countries, indicating that real stock prices exhibit fat tails and non-normality. The significant evidence of nonnormality in Table 1 lend credence to the application of quantile unit root testing for capturing real stock price dynamics in our sample of Asia-Pacific countries.

INSERT TABLE 1 HERE

\section{Empirical results}

\subsection{Univariate unit root tests results}

We begin with univariate unit root or stationary tests such as ADF, Elliot et al. (1996, DF-GLS), Phillips and Perron (1988, PP), Ng and Perron (2001, NP), and Kwiatkowski (1992, KPSS) tests. The ADF, DF-GLS, PP and NP tests are of a unit root null, while the KPSS test is of a stationary null. These univariate unit root regressions are estimated both with and without a time trend. The results are reported in Table 2. The optimal lag is determined using Akaike Information Criteria (AIC) for the ADF and DF-GLS tests. As suggested by Newey and West (1987), we choose bandwidth by the Barlett Kernel for the KPSS, PP and NP tests.

The ADF, DF-GLS and PP tests without a time trend reject the unit root null consistently only for the three countries of Malaysia, Singapore and Taiwan at the $10 \%$ significance level or better. The ADF and DF-GLS tests further reject the unit root null at the $10 \%$ significance level for China and Thailand, respectively. The NP test without a time trend rejects the unit root null only for Taiwan and Singapore respectively at the $5 \%$ and $10 \%$ significance levels. With a time trend, the four univariate unit root tests that we consider consistently reject the unit root null at the 5\% significance level or better for only the four countries, China, Hong Kong, Malaysia and Taiwan. The ADF and DF-GLS tests also reject the unit root null at the $10 \%$ significance level for South Korea and Japan, respectively. For the KPSS test without at time trend, the stationary 
null is not rejected only for New Zealand and Taiwan. The KPSS test with a time trend fails to reject the stationary null only for China, Hong Kong, Malaysia and Thailand.

In sum, the univariate tests either reject the unit root null or cannot reject the stationary null for only a handful of our sample countries which suggests that for the majority of our sample countries, stock prices are non-stationary. Accounting for a deterministic trend does not alter this conclusion. Therefore, the univariate test results imply that stock prices in our sample countries in general do not exhibit mean reversion but instead follow a random walk consistent with the efficient market hypothesis. These results are in line with previous studies such as Shen and Holmes (2014) for China and Taiwan, Wang et al. (2015) for China, Japan and Hong Kong, among others.

INSERT TABLE 2 HERE

\subsection{Quantile unit root test results}

The inability of the univariate tests to reject non-stationarity and market efficiency could be due to their extremely low test power. This provides motivation for the application of quantile unit root testing outlined in Section 3. As Koenker and Xiao (2014) pointed out, there are potential power gains in quantile unit root testing over the ADF test when the shocks exhibit heavy-tailed behavior. Estimation results for quantile unit root testing are reported in Table 3. We conduct the tests for the case of a trend and no trend. However, we present only the results for the case of no trend because the deterministic time trend estimates are not statistically significant in most of the cases.

First, we analyze the QKS test to provide an overall view of real stock prices over the range of quantiles. The QKS test rejects the unit root null hypothesis at the $5 \%$ significance 
level or better in most of the cases except for Australia ${ }^{1}$ and the Philippines. Overall, these results support mean reversion in real stock prices after taking into account the lower and upper quantiles. This global mean reversion finding is highly relevant for investors since it implies that they will have the opportunity to predict future movements in stock prices based on historical behavior in order to earn excess returns. If stock prices are mean reverting in the long run, for instance, then lower returns are followed by higher expected future returns, which could induce investment in equities after a decline in the share market.

INSERT TABLE 3 HERE

Next, we examine the real stock price behavior in each quantile. Overall, the results from Table 3 indicate that the estimates for $\rho_{0}(\tau)$ and $\rho_{1}(\tau)$ are varied across quantiles. Note that $\rho_{0}(\tau)$ reflects the size of the observed shock on real stock price in the $\tau$ th quantile. A negative (positive) sign captures a negative (positive) shock which can be attributed to economic recession (boom). The higher the values of $\rho_{0}(\tau)$, the larger the values of $\tau$ for all countries. Furthermore, the magnitude of the shock at the lower quantiles is not significantly different from zero at the $5 \%$ level for most of the countries except for China, Indonesia, Malaysia, South Korea and Thailand. The sizes of shocks, however, vary across countries. Malaysia (Australia) has the most (least) dispersive shocks, ranging from -0.391 to 0.723 (0.006 to 0.189$)$.

The prime coefficient of interest in Table 3 is the estimated value of $\rho_{1}(\tau)$ and its corresponding unit root test. The results generally indicate that shocks to real stock prices are short-lived in certain quantiles, while the prices contain a unit root wherein the shocks to real prices are more permanent in other quantiles. Specifically, estimates for $\rho_{1}(\tau)$ at the $70 \%$ to

\footnotetext{
${ }^{1}$ The global non-stationarity of real stock prices for Australia is consistent with the efficient market hypothesis and corroborates with Narayan (2005) who employed the unit root test proposed by Caner and Hansen (2001).
} 
90\% quantiles are negative and significant throughout, thereby rejecting the unit-root null for all countries, and implies mean-reversion. Also, the estimates for $\rho_{1}(\tau)$ at the $60 \%$ quantile are significantly different from zero for Indonesia, Japan, Malaysia, Singapore, Thailand, Taiwan. Therefore, the behavior of real stock prices in all countries exhibits mean reversion in high quantiles. This means that positive shocks tend to have transitory effects in real stock prices. In contrast, based on the insignificance of $\rho_{1}(\tau)$, non-stationarity tends to prevail in low quantiles ( $50 \%$ and below) in most of the countries. This means that negative shocks tend to have permanent effects on real stock prices.

Figure 2 illustrates the above estimates for $\rho_{0}(\tau)$ and $\rho_{1}(\tau)$ along with their $95 \%$ confidence intervals obtained from the bootstrapping procedure. The estimates for $\rho_{0}(\tau)$ in most cases tend to increase, passing through the zero point at least at the $60 \%$ quantile or higher. Additionally, the estimates for $\rho_{0}(\tau)$ are higher for Malaysia and Taiwan, which can be attributed to large exogenous shocks (such as financial crises or critical economic events) to stock prices of these two countries. These shocks might push the estimate of $\rho_{0}(\tau)$ up or down. As for the autoregressive coefficient $\rho_{1}(\tau)$, we find that their values decrease with $\tau$ in the cases of China, Indonesia, Japan, Malaysia, South Korea and Thailand. Indeed, the values of $\rho_{1}(\tau)$ in these countries are more negative in the high quantiles. By contrast, Australia, Hong Kong, New Zealand, Philippines, Singapore and Taiwan are characterized by $\rho_{1}(\tau)$, which seems to have no significant variation across the quantiles. In the cases of Australia and the Philippines, they mostly exhibit a zero slope inside the confidence interval thereby lending visual support for these two countries being non-stationary in majority of the quantiles. In addition, combining the results of $\rho_{0}(\tau)$ and $\rho_{1}(\tau)$ shows that in the presence of positive shocks, real stock prices would revert to its long-run equilibrium level, but extreme negative shocks seem to lack the ability to induce mean reversion. This finding is consistent with Shen and Holmes (2014) who 
found that real stock prices of Asia-Pacific countries are characterized by two stationary regimes with different speeds of adjustment based on Markov regime-switching approach.

INSERT FIGURE 2 HERE

Table 3 also reports the results of HLs associated with the quantiles where real stock prices are stationary. For each country, the stationary cases of $\rho_{1}(\tau)$ are characterized by very different dynamic properties. To be specific, there are marked differences in the estimated HLs in the stationary cases of $\rho_{1}(\tau)$, especially in the highest quantile (90\%). Malaysia and Thailand are characterized by a much faster speed of adjustment with HLs of 4 to 5 months, compared with a relatively comparable speed of adjustment with HLs of 4 to 11 months for Hong Kong, Indonesia, Singapore, South Korea and Thailand. These short HLs indicate that real stock prices can quickly return to the long-run level when the stock prices are hit by a large positive shock. Meanwhile, New Zealand, China and Japan have a relatively slow speed of adjustment with HLs of 12 to 13 months. In contrast, Australia and the Philippines are characterized by a much slower speed of adjustment with HLs of 21 to 22 months. However, in the extreme low quantile (10\%), the estimated HLs are infinite in most of the cases, meaning that stock prices have no tendency to revert to its long-run equilibrium level.

The above results indicate that that the dynamic behavior of real stock prices in our sample countries is asymmetric. That is, real stock prices are far from persistent and therefore mean-reverting in the upper quantiles, but contain a unit root and therefore non-stationary in the lower quantiles. According to Shen and Holmes (2014), such asymmetry can be due to the existence of market frictions and transaction costs. If bid-ask spreads, short-selling and borrowing constraints are present, small deviations from the equilibrium are expected to be unprofitable for investors. Meanwhile, only the presence of large and profitable deviations from the equilibrium would induce ensuing revision to the equilibrium. Consequently, the dynamic 
behavior of equity returns will vary depending on the size of the deviation from equilibrium, and hence leads to asymmetric behavior of the equity returns (Dumas, 1992; He and Modest, 1995; Shleifer, 2000).

From a policy perspective, our empirical results suggest that real stock prices do not follow a mean reverting process when a large negative shock such as financial crisis hits stock prices. In this situation, stock market inefficiency may occur so that the authorities may need to intervene through equity market invention policies in order to help investors in forecasting future movements in stock prices more accurately. On the contrary, real stock prices are mean reverting when a positive shock such as economic boom hits the stock market. It means that future movements in stock prices can be predicted based on past stock prices. This suggests that institutional and regulatory mechanisms will not be so important, compared with the situation where historical stock price movements could be used in order to earn excess returns.

\subsection{Quantile regression results before and after the global financial crisis}

We first consider whether our findings in Table 3 remain robust before the global financial crisis. Since economies around the world have experienced financial market turmoil, this may have impacted on the analysis. To this end, we divide our sample into two subsample periods from 1987:M1-2007:M12 and 2010:M1-2018:M8 for the before and after the global financial crisis periods, respectively.

Table 4 presents new estimation results based on the two subsample periods. In comparison with the results in Table 3, the counterparts in Table 4 show the following observations. First, the QKS still indicates that real stock prices are globally mean-reverting but only for China, Malaysia, New Zealand, South Korea and Taiwan. In addition, the QKS test still fails to reject the unit root null for Australia and the Philippines. In contrast to the preceding 
results, the QKS test exhibits low power performance and cannot reject the unit root null in real stock prices for Hong Kong, Indonesia, Japan, Singapore and Taiwan.

Table 4 also shows that although the values of $\rho_{0}(\tau)$ are slightly different from those in Table 3, they similarly increase as the quantiles get large. Finally, except for Australia, Philippines, Singapore and Thailand, the persistence of real stock prices is still asymmetric depending on the signs and sizes of the shocks. The estimates for $\rho_{1}(\tau)$ are not significantly different from zero across all quantiles for Australia or for most of the quantiles in the cases of the Philippines, Singapore and Thailand. This suggests that real stock prices follow a unit root process in the subsample period before the global financial crisis. Furthermore, the estimated HLs increase in most of the countries before the global financial crisis, while Japan, New Zealand and South Korea are characterized by a much slower speed of adjustment. For example, in New Zealand the estimated HLs noticeably decrease to 13.33, 9.95 and 8.06 from 33.86, 23.93 and 12.05 for $70 \%, 80 \%$ and $90 \%$ quantiles, respectively.

Next, we consider whether the behavior of real stock prices changed after the global financial crisis and report the results in Table 5. With the exception of Japan and New Zealand, the QKS test still indicates that real stock prices are globally mean-reverting in most countries including Australia and the Philippines which were previously globally non-stationary in Table 3. This finding implies that stock prices follow a stationary process and more so after the global financial crisis. Also, the estimates for $\rho_{0}(\tau)$ differ slightly from those in Table 3 but they still indicate that the impact of positive shocks on stock prices is larger than negative shocks even after the global financial crisis. Furthermore, there is still asymmetry in the persistence of stock prices in most countries but its degree generally increased in most quantiles. Indeed, the estimated values of $\rho_{1}(\tau)$ are now significantly different from zero in most quantiles for majority of the cases. 
In view of HLs, the findings of asymmetry in the speed of real stock price adjustment across different quantiles remains for most countries, except for New Zealand. In contrast to the preceding results, however, Table 5 shows that most of the countries are characterized by a much faster speed of adjustment in the stationary cases of $\rho_{1}(\tau)$ after the global financial crisis. One plausible reason for this faster speed of mean reversion is the strong response from arbitrage and investment opportunities and activities that originated from a large disequilibrium in the stock market during the global financial crisis. Investors may have overreacted not only to local news, but also to news originating in the other markets even in the aftermath of the shock of global financial crisis. The significant disequilibrium in these equity markets would not be expected to attract a strong response from international speculators.

Finally, we take into account a possible structural break that could have resulted from the 2008-2009 global financial crisis. Neglecting structural breaks could lead to spuriously high estimates of the degree of persistence. To this end, we capture the possible mean shift by following Tsong and Lee (2011) by re-writing $\Delta s_{t}$ in Eq. (1) as follows:

$$
\Delta z_{t}=\rho_{0}+\rho_{1} z_{t-1}+\sum_{i=1}^{q} \gamma_{i} \Delta z_{t-i}+\varepsilon_{t}
$$

where $z_{t}=\pi_{t}-\hat{\mu}_{0}-\hat{\mu}_{1} D_{t}$. Here $\hat{\mu}_{0}$ and $\hat{\mu}_{0}$ are ordinary least square (OLS) estimates of $\mu_{0}$ and $\mu_{1}$, respectively, obtained from the regression of $s_{t}$ on $\left(1, D_{t}\right)^{\prime}$ and $D_{t}$ is an indicator function taking unity if $t \geq s_{t}$, and zero otherwise, with $s_{t}$ being a known start date of the global financial crisis. On the basis of the new calculation of $\pi_{t}$ in Eq.(7), Table 6 presents re-estimated QKS test results, $\rho_{0}(\tau)$ and $\rho_{1}(\tau)$ coefficients, and HLs obtained using the same methodology as described Section 2.

INSERT TABLE 6 HERE 
As shown in Table 6, the main findings in Table 3 remain unchanged. The results are summarized as follows. First, the QKS test still indicates that real stock prices are globally mean-reverting in most of the cases except for Australia and the Philippines. Second, the estimates for $\rho_{0}(\tau)$ still increase with quantiles. Finally, the persistence of real stock prices is still asymmetric depending on the signs and sizes of the shocks. In particular, the stationarity (non-stationarity) of real stock prices tends to prevail in high (low) quantiles.

\section{Conclusion}

In this paper, we examined the dynamic behavior of real stock prices and the impact of the GFC on share market efficiency. In contrast with Shen and Holmes (2014a), who used a Markov regime-switching unit root testing, and Anagnotidis et al. (2016), who applied the Generalized Hurst Exponent method, we employed the quantile unit root testing developed by Koenker and Xiao (2004), which accounts for possible asymmetric speed of adjustment of stock prices toward to its long-run equilibrium level.

The quantile unit root testing results suggest stationarity in real stock prices at the upper quantiles only, which are characterized by a varied speed of adjustment. The results further suggest that there are asymmetries in the dynamic adjustments of real stock prices, which indicates that large positive shocks tend to induce strong mean reversion but the same does not hold for large negative shocks. Thus, any equity market intervention policies designed to influence the behavior of the real stock prices without taking account of the signs and sizes of shocks affecting the stock markets is likely to be ineffective. We also find that real stock prices in most of our sample of 12 Asia-Pacific countries exhibit more significant mean-reverting patterns with a faster speed of adjustment after the GFC, signaling increased investment in equities after a market downturn. 


\section{References:}

Ahmad, A. H., Daud, S. N. M., \& Azman-Saini, W. N. W. (2010). Efficient market hypothesis in emerging markets: Panel data evidence with multiple breaks and cross sectional dependence. Economics Bulletin, 30(4), 2987-2995.

Akarim, Y. D., \& Sevim, S. (2013). The impact of mean reversion model on portfolio investment strategies: Empirical evidence from emerging markets. Economic Modelling, 31, 453-459.

Anagnostidis, P., Varsakelis, C., \& Emmanouilides, C. J. (2016). Has the 2008 financial crisis affected stock market efficiency? The case of Eurozone. Physica A: Statistical Mechanics and its Applications, 447, 116-128.

Ball, R., \& Kothari, S. P. (1989). Nonstationary expected returns: Implications for tests of market efficiency and serial correlation in returns. Journal of Financial Economics, 25(1), 51-74.

Bose, N. (2005). Endogenous growth and the emergence of equity finance. Journal of Development Economics, 77(1), 173-188.

Chan, K. C. (1988). On the contrarian investment strategy. Journal of business, 147-163.

Chaudhuri, K., \& Wu, Y. (2003). Random walk versus breaking trend in stock prices: Evidence from emerging markets. Journal of Banking \& Finance, 27(4), 575-592.

Chen, S. L., \& Kim, H. (2011). Nonlinear mean reversion across national stock markets: Evidence from emerging Asian markets. International Economic Journal, 25(2), 239250.

Conrad, J., \& Kaul, G. (1993). Long-term market overreaction or biases in computed returns?. The Journal of Finance, 48(1), 39-63.

De Bondt, W. F., \& Thaler, R. (1985). Does the stock market overreact?. The Journal of Finance, 40(3), 793-805.

Elliott, G., T. J. Rothenberg, and J. H. Stock. (1996). Efficient tests for an autoregressive unit root. Econometrica, 64 (4): 813-836.

Fama, E.F. (1970). Efficient capital markets: A review of theory and empirical work. Journal of Finance, 25(2): 383-417.

Fama, E. F., \& French, K. R. (1988). Dividend yields and expected stock returns. Journal of Financial Economics, 22(1), 3-25.

Groenewold, N., Tang, S. H. K., \& Wu, Y. (2003). The efficiency of the Chinese stock market and the role of the banks. Journal of Asian Economics, 14(4), 593-609. 
Hoque, H. A., Kim, J. H., \& Pyun, C. S. (2007). A comparison of variance ratio tests of random walk: A case of Asian emerging stock markets. International Review of Economics \& Finance, 16(4), 488-502.

Horta, P., Lagoa, S., \& Martins, L. (2014). The impact of the 2008 and 2010 financial crises on the Hurst exponents of international stock markets: Implications for efficiency and contagion. International Review of Financial Analysis, 35, 140-153.

Hosseinkouchack, M., \& Wolters, M. H. (2013). Do large recessions reduce output permanently?. Economics Letters, 121(3), 516-519.

Katris, C., \& Daskalaki, S. (2013). Effect of economic crisis in efficiency and predictability of Greek and German stock indices. In C. Frangos (Eds.), Proceedings of the 3rd International Conference: Quantitative and qualitative methodologies in the economic and administrative sciences (pp. 224-230). Athens, Greece.

Kim, J. H., \& Shamsuddin, A. (2008). Are Asian stock markets efficient? Evidence from new multiple variance ratio tests. Journal of Empirical Finance, 15(3), 518-532.

Koenker, R., \& Xiao, Z. (2004). Unit Root Quantile Autoregression Inference. Journal of the American Statistical Association, 99(467), 775-787.

Kwiatkowski, D., Phillips, P. C. B., Schmidt, P., \& Shin, Y. (1992). Testing the null hypothesis of stationarity against the alternative of a unit root. how sure are we that economic time series have a unit root? Journal of Econometrics, 54(1-3), 159-178.

Lean, H. H., \& Smyth, R. (2007). Do Asian stock markets follow a random walk? Evidence from LM unit root tests with one and two structural breaks. Review of Pacific Basin Financial Markets and Policies, 10(01), 15-31.

Lee, C. C., Tsong, C. C., \& Lee, C. F. (2014). Testing for the efficient market hypothesis in stock prices: International evidence from nonlinear heterogeneous panels. Macroeconomic Dynamics, 18(4), 943-958.

Lee, C. C., Lee, J. D., \& Lee, C. C. (2010). Stock prices and the efficient market hypothesis: Evidence from a panel stationary test with structural breaks. Japan and the World Economy, 22(1), 49-58.

Lim, K. P., \& Liew, V. K. S. (2007). Nonlinear mean reversion in stock prices: Evidence from Asian markets. Applied Financial Economics Letters, 3(1), 25-29.

Lim, K. P., Brooks, R. D., \& Kim, J. H. (2008). Financial crisis and stock market efficiency: Empirical evidence from Asian countries. International Review of Financial Analysis, 17(3), 571-591.

Lim, K. P., \& Brooks, R. (2011). The evolution of stock market efficiency over time: A survey of the empirical literature. Journal of Economic Surveys, 25(1), 69-108.

Lu, Y. C., Chang, T., Hung, K., \& Liu, W. C. (2010). Mean reversion in G-7 stock prices: Further evidence from a panel stationary test with multiple structural breaks. Mathematics and Computers in Simulation, 80(10), 2019-2025. 
Mauro, P. (2003). Stock returns and output growth in emerging and advanced economies. Journal of Development Economics, 71(1), 129-153.

Mishra, A., \& Mishra, V. (2011). Is the Indian stock market efficient? Evidence from a TAR model with an autoregressive unit root. Applied Economics Letters, 18(5), 467-472.

Munir, Q., \& Mansur, K. (2009). Is Malaysian stock market efficient? Evidence from threshold unit root tests. Economics Bulletin, 29(2), 1359-1370.

Narayan, P. K., \& Smyth, R. (2004). Is South Korea's stock market efficient?. Applied Economics Letters, 11(11), 707-710.

Narayan, P.K. (2005). Are the Australian and New Zealand stock prices nonlinear with a unit root?. Applied Economics, 37(18), 2161-2166.

Narayan, P. K., \& Smyth, R. (2005). Are OECD stock prices characterized by a random walk? Evidence from sequential trend break and panel data models. Applied Financial Economics, 15(8), 547-556.

Narayan, P. K., \& Smyth, R. (2007). Mean reversion versus random walk in G7 stock prices: Evidence from multiple trend break unit root tests. Journal of International Financial Markets, Institutions and Money, 17(2), 152-166.

Narayan, P. K. (2008). Do shocks to G7 stock prices have a permanent effect?: Evidence from panel unit root tests with structural change. Mathematics and Computers in Simulation, 77(4), 369-373.

Narayan, P. K., Narayan, S., \& Mishra, S. (2013). Has the structural break slowed down growth rates of stock markets?. Economic Modelling, 30, 595-601.

Newey, W. K., \& West, K. D. (1987). A simple, positive semi-definite, heteroskedasticity and autocorrelation consistent covariance matrix. Econometrica (1986-1998), 55(3), 703.

Ng, S., \& Perron, P. (2001). Lag length selection and the construction of unit root tests with good size and power. Econometrica, 69(6), 1519-1554.

Phengpis, C. (2006). Are emerging stock market price indices really stationary?. Applied Financial Economics, 16(13), 931-939.

Phillips, P. C. B., \& Peron, P. (1988). Testing for unit roots in time series. Biometrika 75, 335-346.

Poterba, J. M., \& Summers, L. H. (1988). Mean reversion in stock prices: Evidence and implications. Journal of financial economics, 22(1), 27-59.

Qian, X. Y., Song, F. T., \& Zhou, W. X. (2008). Nonlinear behaviour of the Chinese SSEC index with a unit root: Evidence from threshold unit root tests. Physica A: Statistical Mechanics and Its Applications, 387(2-3), 503-510. 
Richards, A. J. (1997). Winner-loser reversals in national stock market indices: Can they be explained?. The Journal of Finance, 52(5), 2129-2144.

Rizvi, S. A. R., \& Arshad, S. (2016). How does crisis affect efficiency? An empirical study of East Asian markets. Borsa Istanbul Review, 16(1), 1-8.

Sensoy, A., \& Tabak, B. M. (2015). Time-varying long term memory in the European Union stock markets. Physica A: Statistical Mechanics and its Applications, 436, 147-158.

Setianto, R. H., \& Manap, T. A. A. (2011). The Behavior of Indonesian Stock Market: Structural Breaks and Nonlinearity. Gadjah Mada International Journal of Business, 13(3).

Shefrin, H., \& Statman, M. (1985). The disposition to sell winners too early and ride losers too long: Theory and evidence. The Journal of finance, 40(3), 777-790.

Shen, X., \& Holmes, M. J. (2014a). Do Asia-Pacific stock prices follow a random walk? A regime-switching perspective. Applied Economics Letters, 21(3), 189-195.

Shen, X., \& J. Holmes, M. (2014b). Are stock prices stationary? Some new evidence from a panel data approach. Studies in Economics and Finance, 31(4), 387-405.

Summers, L. H. (1986). Does the stock market rationally reflect fundamental values?. The Journal of Finance, 41(3), 591-601.

Smith, G. (2012). The changing and relative efficiency of European emerging stock markets. The European Journal of Finance, 18(8), 689-708.

Tan, S.H., Habibullah, M.S., \& Khong, R. (2010). Non-linear unit root properties of stock prices: Evidence from India, Pakistan and Sri Lanka. Economics Bulletin, 30(1), 274281.

Tsong, C. C., \& Lee, C. F. (2011). Asymmetric inflation dynamics: Evidence from quantile regression analysis. Journal of Macroeconomics, 33(4), 668-680.

Wang, J., Zhang, D., \& Zhang, J. (2015). Mean reversion in stock prices of seven Asian stock markets: Unit root test and stationary test with Fourier functions. International Review of Economics \& Finance, 37, 157-164.

Zarowin, P. (1990). Size, seasonality, and stock market overreaction. Journal of Financial and Quantitative analysis, 25(1), 113-125. 
Table 1. Summary statistics for monthly real stock prices

\begin{tabular}{llllll}
\hline Country & Mean & S.D. & Skewness & Kurtosis & JB stat. $(p$-value $)$ \\
\hline Australia & 94.552 & 21.329 & 0.366 & 3.262 & $8.365^{* *}(0.015)$ \\
China & 74.084 & 41.755 & 0.587 & 3.193 & $19.568^{* * *}(0.000)$ \\
Hong Kong & 94.289 & 26.935 & 0.075 & 2.162 & $10.034^{* * *}(0.007)$ \\
Indonesia & 85.669 & 35.874 & -0.359 & 1.795 & $27.215^{* * *}(0.000)$ \\
Japan & 93.889 & 23.733 & -0.270 & 2.022 & $17.277^{* * *}(0.000)$ \\
Malaysia & 91.260 & 19.221 & 0.299 & 3.569 & $9.448^{* * *}(0.009)$ \\
New Zealand & 134.978 & 24.315 & 0.000 & 2.122 & $10.676^{* * * *}(0.005)$ \\
Philippines & 139.828 & 60.362 & 0.792 & 3.107 & $34.842^{* * *}(0.000)$ \\
Singapore & 144.125 & 32.567 & -0.167 & 2.065 & $13.636^{* * *}(0.001)$ \\
South Korea & 78.626 & 31.772 & 0.169 & 1.786 & $21.975^{* * *}(0.000)$ \\
Taiwan & 113.331 & 22.666 & 0.446 & 3.527 & $14.844^{* * *}(0.001)$ \\
Thailand & 135.698 & 67.150 & 1.016 & 3.887 & $67.959^{* * *}(0.000)$ \\
\hline
\end{tabular}

Notes: JB stat. denotes the Jarque-Bera normality test, which is $\chi^{2}(2)$ distributed asymptotically. 
Table 2. Results for univariate unit root tests on monthly real stock prices

\begin{tabular}{|c|c|c|c|c|c|c|c|c|c|c|}
\hline \multirow[b]{2}{*}{ Country } & \multicolumn{2}{|l|}{$\mathrm{ADF}$} & \multicolumn{2}{|l|}{ DF-GLS } & \multicolumn{2}{|l|}{$\mathrm{PP}$} & \multicolumn{2}{|l|}{$\mathrm{NP}$} & \multicolumn{2}{|l|}{ KPSS } \\
\hline & No trend & With trend & No trend & With trend & No trend & With trend & No trend & With trend & No trend & With trend \\
\hline Australia & -2.188 & -2.533 & -0.154 & -1.973 & -2.255 & -2.704 & -0.218 & -2.105 & $1.316^{* * *}$ & $0.225^{* * *}$ \\
\hline China & $-2.713^{*}$ & $-4.551^{* * *}$ & -1.074 & $-4.397^{* * *}$ & -2.384 & $-3.788^{* *}$ & -0.895 & $-3.629^{* * *}$ & $1.650^{* * *}$ & 0.068 \\
\hline Hong Kong & -2.395 & $-3.711^{* *}$ & -0.464 & $-3.246^{* *}$ & -2.473 & $-3.805^{* *}$ & -0.510 & $-3.223^{* *}$ & $1.659^{* * *}$ & 0.086 \\
\hline Indonesia & -1.939 & -2.549 & -1.050 & -1.207 & -2.121 & -2.754 & -1.147 & -1.279 & $0.748^{* * *}$ & $0.409^{* * *}$ \\
\hline Japan & -2.564 & -2.864 & -1.579 & $-2.828^{*}$ & -2.229 & -2.412 & -1.324 & -2.335 & $0.686^{* *}$ & $0.199^{* *}$ \\
\hline Malaysia & $-3.488^{* * *}$ & $-3.77^{6^{* *}}$ & $-1.770^{*}$ & $-3.402^{* *}$ & $-3.221^{* *}$ & $-3.394^{*}$ & -1.559 & $-2.963^{* *}$ & $0.585^{* *}$ & 0.078 \\
\hline New Zealand & -2.320 & -2.336 & -0.445 & -1.719 & -2.273 & -2.275 & -0.329 & -1.621 & 0.204 & $0.139^{*}$ \\
\hline Philippines & -1.658 & -1.687 & -1.080 & -1.469 & -1.946 & -2.030 & -1.213 & -1.593 & $0.418^{*}$ & $0.332^{* * *}$ \\
\hline Singapore & $-2.862^{*}$ & -2.643 & $-1.667^{*}$ & -2.240 & $-2.573^{*}$ & -2.405 & $-1.616^{*}$ & -2.111 & $0.365^{*}$ & $0.150^{* *}$ \\
\hline South Korea & -1.302 & $-3.320^{*}$ & -0.797 & -2.522 & -1.091 & $-3.236^{*}$ & -0.602 & -2.367 & $1.841^{* * *}$ & $0.212^{* *}$ \\
\hline Taiwan & $-3.735^{* * *}$ & $-3.792^{* *}$ & $-2.299^{* *}$ & $-3.606^{* * *}$ & $-3.582^{* * *}$ & $-3.630^{* *}$ & $-2.434^{* *}$ & $-3.339^{* *}$ & 0.141 & $0.124^{*}$ \\
\hline Thailand & -1.775 & -1.666 & $-1.778^{*}$ & -1.777 & -1.589 & -1.542 & -0.895 & $-3.629^{* * *}$ & $1.650^{* * *}$ & 0.068 \\
\hline
\end{tabular}

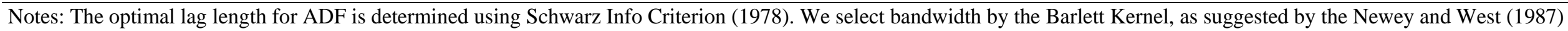
test for PP and NP. ***, ** and * denote significance at the $1 \%, 5 \%$ and $10 \%$ level, respectively. 
Table 3. Quantile ADF unit root results for the whole sample period, January 1991-August 2018

\begin{tabular}{|c|c|c|c|c|c|c|c|c|c|c|}
\hline Country & $\tau$ & 0.1 & 0.2 & 0.3 & 0.4 & 0.5 & 0.6 & 0.7 & 0.8 & 0.9 \\
\hline \multirow[t]{6}{*}{ Australia } & $\rho_{0}(\tau)$ & 0.078 & 0.006 & $0.116^{* *}$ & 0.066 & $0.085^{*}$ & $0.100^{* *}$ & $0.093^{*}$ & $0.164^{* * *}$ & $0.189^{* * *}$ \\
\hline & $p$-value & 0.282 & 0.916 & 0.017 & 0.132 & 0.053 & 0.032 & 0.067 & 0.004 & 0.005 \\
\hline & $\rho_{1}(\tau)$ & $-0.028 *$ & -0.009 & $-0.029^{* *}$ & -0.015 & -0.017 & -0.018 & -0.015 & $-0.028^{* *}$ & $-0.031^{* *}$ \\
\hline & $p$-value & 0.072 & 0.325 & 0.047 & 0.448 & 0.272 & 0.102 & 0.118 & 0.017 & 0.021 \\
\hline & Half-lives & 24.099 & $\infty$ & 23.362 & $\infty$ & $\infty$ & $\infty$ & $\infty$ & 24.216 & 22.146 \\
\hline & $\mathrm{QKS} / p$-value & $2.745(0.1$ & & & & & & & & \\
\hline \multirow[t]{6}{*}{ China } & $\rho_{0}(\tau)$ & $-0.144^{* * *}$ & $-0.108^{* *}$ & -0.059 & 0.014 & 0.047 & $0.082^{* *}$ & $0.179^{* * *}$ & $0.292^{* * *}$ & $0.341^{* * *}$ \\
\hline & $p$-value & 0.008 & 0.016 & 0.144 & 0.712 & 0.212 & 0.032 & 0.000 & 0.000 & 0.000 \\
\hline & $\rho_{1}(\tau)$ & 0.008 & 0.011 & 0.006 & -0.006 & -0.009 & -0.013 & $-0.031^{* * *}$ & $-0.052^{* * *}$ & $-0.052^{* * *}$ \\
\hline & $p$-value & 0.665 & 0.844 & 0.797 & 0.459 & 0.434 & 0.163 & 0.002 & 0.000 & 0.000 \\
\hline & Half-lives & $\infty$ & $\infty$ & $\infty$ & $\infty$ & $\infty$ & $\infty$ & 21.904 & 12.971 & 12.886 \\
\hline & $\mathrm{QKS} / p$-value & \multicolumn{9}{|c|}{$3.740(0.024)^{* *}$} \\
\hline \multirow[t]{6}{*}{ Hong Kong } & $\rho_{0}(\tau)$ & 0.067 & -0.070 & -0.024 & 0.001 & 0.041 & $0.129^{* *}$ & $0.267^{* * *}$ & $0.364^{* * *}$ & $0.486^{* * *}$ \\
\hline & $p$-value & 0.444 & 0.339 & 0.706 & 0.990 & 0.497 & 0.034 & 0.000 & 0.000 & 0.000 \\
\hline & $\rho_{1}(\tau)$ & -0.032 & 0.005 & 0.000 & -0.002 & -0.008 & -0.025 & $-0.051^{* * *}$ & $-0.068^{* * *}$ & $-0.090^{* * *}$ \\
\hline & $p$-value & 0.163 & 0.654 & 0.596 & 0.624 & 0.584 & 0.118 & 0.003 & 0.000 & 0.000 \\
\hline & Half-lives & $\infty$ & $\infty$ & $\infty$ & $\infty$ & $\infty$ & $\infty$ & 13.257 & 9.829 & 7.358 \\
\hline & $\mathrm{QKS} / p$-value & \multicolumn{9}{|c|}{$4.582(0.012)^{* *}$} \\
\hline \multirow[t]{6}{*}{ Indonesia } & $\rho_{0}(\tau)$ & $-0.148^{* *}$ & $-0.101^{* *}$ & -0.069 & -0.053 & 0.029 & $0.146^{* * *}$ & $0.237^{* * *}$ & $0.244^{* * *}$ & $0.401^{* * *}$ \\
\hline & $p$-value & 0.016 & 0.041 & 0.125 & 0.222 & 0.491 & 0.001 & 0.000 & 0.000 & 0.000 \\
\hline & $\rho_{1}(\tau)$ & 0.012 & 0.011 & 0.009 & 0.008 & -0.005 & $-0.028^{* *}$ & $-0.045^{* * *}$ & $-0.042^{* * *}$ & $-0.069^{* * *}$ \\
\hline & $p$-value & 0.733 & 0.770 & 0.862 & 0.878 & 0.609 & 0.019 & 0.000 & 0.000 & 0.000 \\
\hline & Half-lives & $\infty$ & $\infty$ & $\infty$ & $\infty$ & $\infty$ & 24.279 & 15.218 & 15.995 & 9.701 \\
\hline & $\mathrm{QKS} / p$-value & \multicolumn{9}{|c|}{$4.707(0.013)^{* *}$} \\
\hline
\end{tabular}

Notes: All the $p$-values are calculated with the bootstrap method with 5000 replications. For $\hat{\rho}_{0}(\tau)$ the null of zero is tested with the student- $t$ test, while for $\hat{\rho}_{1}(\tau)$, the unit-root null is tested with the $t_{n}(\tau)$ statistic. ${ }^{* * *},{ }^{* *}$ and ${ }^{*}$ denote significance at the 1,5 and $10 \%$ levels. 
Table 3. (Continued)

\begin{tabular}{|c|c|c|c|c|c|c|c|c|c|c|}
\hline Country & $\tau$ & 0.1 & 0.2 & 0.3 & 0.4 & 0.5 & 0.6 & 0.7 & 0.8 & 0.9 \\
\hline \multirow[t]{6}{*}{ Japan } & $\rho_{0}(\tau)$ & -0.054 & 0.079 & 0.100 & $0.145^{* *}$ & $0.158^{* *}$ & $0.131^{* *}$ & $0.215^{* * *}$ & $0.298^{* * *}$ & $0.323^{* * *}$ \\
\hline & $p$-value & 0.593 & 0.303 & 0.136 & 0.020 & 0.010 & 0.039 & 0.002 & 0.000 & 0.001 \\
\hline & $\rho_{1}(\tau)$ & -0.003 & -0.024 & $-0.025^{*}$ & $-0.032^{* *}$ & $-0.032^{*}$ & $-0.024^{*}$ & $-0.038^{* * *}$ & $-0.051^{* * *}$ & $-0.052^{* * *}$ \\
\hline & $p$-value & 0.445 & 0.157 & 0.079 & 0.049 & 0.092 & 0.077 & 0.009 & 0.002 & 0.001 \\
\hline & Half-lives & $\infty$ & $\infty$ & 27.088 & 21.468 & 21.572 & 29.053 & 17.816 & 13.195 & 13.019 \\
\hline & QKS/p-value & \multicolumn{9}{|c|}{$3.162(0.031)^{* *}$} \\
\hline \multirow[t]{6}{*}{ Malaysia } & $\rho_{0}(\tau)$ & $-0.391^{* * *}$ & -0.067 & $-0.113^{*}$ & 0.046 & $0.155^{* *}$ & $0.212^{* * *}$ & $0.325^{* * *}$ & $0.451^{* * *}$ & $0.723^{* * *}$ \\
\hline & $p$-value & 0.000 & 0.358 & 0.094 & 0.466 & 0.014 & 0.001 & 0.000 & 0.000 & 0.000 \\
\hline & $\rho_{1}(\tau)$ & 0.071 & 0.006 & 0.020 & -0.012 & $-0.033^{*}$ & $-0.044^{* *}$ & $-0.066^{* * *}$ & $-0.090^{* * *}$ & $-0.144^{* * *}$ \\
\hline & $p$-value & 0.994 & 0.675 & 0.966 & 0.347 & 0.087 & 0.019 & 0.002 & 0.000 & 0.000 \\
\hline & Half-lives & $\infty$ & $\infty$ & $\infty$ & $\infty$ & 20.506 & 15.553 & 10.190 & 7.342 & 4.444 \\
\hline & QKS/p-value & \multicolumn{9}{|c|}{$6.913(0.000)^{* * *}$} \\
\hline \multirow[t]{6}{*}{ New Zealand } & $\rho_{0}(\tau)$ & 0.043 & 0.028 & 0.093 & $0.156^{* * *}$ & $0.151^{* *}$ & $0.109^{*}$ & $0.120^{*}$ & $0.168^{* *}$ & $0.318^{* * *}$ \\
\hline & $p$-value & 0.641 & 0.698 & 0.140 & 0.008 & 0.010 & 0.072 & 0.063 & 0.017 & 0.000 \\
\hline & $\rho_{1}(\tau)$ & -0.018 & -0.011 & -0.022 & $-0.033^{*}$ & -0.030 & -0.020 & $-0.020^{* *}$ & $-0.029^{* *}$ & $-0.056^{* * *}$ \\
\hline & $p$-value & 0.296 & 0.349 & 0.165 & 0.061 & 0.119 & 0.105 & 0.046 & 0.016 & 0.008 \\
\hline & Half-lives & $\infty$ & $\infty$ & $\infty$ & 20.917 & $\infty$ & $\infty$ & 33.860 & 23.927 & 12.051 \\
\hline & QKS/p-value & \multicolumn{9}{|c|}{$3.175(0.085)^{*}$} \\
\hline \multirow[t]{6}{*}{ Philippines } & $\rho_{0}(\tau)$ & -0.029 & -0.001 & 0.022 & 0.026 & 0.041 & 0.066 & $0.121^{* *}$ & $0.202^{* * *}$ & $0.237^{* * *}$ \\
\hline & $p$-value & 0.689 & 0.988 & 0.657 & 0.573 & 0.372 & 0.164 & 0.018 & 0.000 & 0.001 \\
\hline & $\rho_{1}(\tau)$ & -0.012 & -0.011 & -0.011 & -0.008 & -0.007 & -0.010 & $-0.017^{*}$ & $-0.030^{* *}$ & $-0.032^{* *}$ \\
\hline & $p$-value & 0.300 & 0.290 & 0.293 & 0.478 & 0.664 & 0.350 & 0.087 & 0.011 & 0.029 \\
\hline & Half-lives & $\infty$ & $\infty$ & $\infty$ & $\infty$ & $\infty$ & $\infty$ & 40.244 & 22.718 & 21.505 \\
\hline & QKS/p-value & \multicolumn{9}{|c|}{$2.571(0.140)$} \\
\hline
\end{tabular}

Notes: All the $p$-values are calculated with the bootstrap method with 5000 replications. For $\hat{\rho}_{0}(\tau)$ the null of zero is tested with the student- $t$ test, while for $\hat{\rho}_{1}(\tau)$, the unit-root null is tested with the $t_{n}(\tau)$ statistic. ${ }^{* * *, * *}$ and ${ }^{*}$ denote significance at the 1,5 and $10 \%$ levels. 
Table 3. (Continued)

\begin{tabular}{|c|c|c|c|c|c|c|c|c|c|c|}
\hline Country & $\tau$ & 0.1 & 0.2 & 0.3 & 0.4 & 0.5 & 0.6 & 0.7 & 0.8 & 0.9 \\
\hline \multirow[t]{6}{*}{ Singapore } & $\rho_{0}(\tau)$ & $0.187^{*}$ & 0.048 & 0.021 & 0.082 & $0.164^{* *}$ & $0.205^{* * *}$ & $0.249^{* * *}$ & $0.313^{* * *}$ & $0.458^{* * *}$ \\
\hline & $p$-value & 0.064 & 0.568 & 0.776 & 0.242 & 0.019 & 0.004 & 0.001 & 0.000 & 0.000 \\
\hline & $\rho_{1}(\tau)$ & $-0.056^{*}$ & -0.019 & -0.009 & -0.020 & $-0.035^{*}$ & $-0.042^{* *}$ & $-0.049^{* * *}$ & $-0.060^{* * *}$ & $-0.088^{* * *}$ \\
\hline & $p$-value & 0.059 & 0.262 & 0.417 & 0.279 & 0.079 & 0.024 & 0.006 & 0.002 & 0.001 \\
\hline & Half-lives & 12.100 & $\infty$ & $\infty$ & $\infty$ & 19.210 & 16.170 & 13.724 & 11.129 & 7.546 \\
\hline & QKS/p-value & \multicolumn{9}{|c|}{$3.935(0.027)^{* *}$} \\
\hline \multirow[t]{6}{*}{ South Korea } & $\rho_{0}(\tau)$ & $-0.306^{* * *}$ & $-0.200^{* * *}$ & $-0.172^{* * *}$ & $-0.090^{* *}$ & -0.027 & $0.089^{* *}$ & $0.193^{* * *}$ & $0.293^{* * *}$ & $0.546^{* * *}$ \\
\hline & $p$-value & 0.000 & 0.000 & 0.000 & 0.043 & 0.528 & 0.042 & 0.000 & 0.000 & 0.000 \\
\hline & $\rho_{1}(\tau)$ & 0.052 & 0.034 & 0.032 & 0.017 & 0.007 & -0.016 & $-0.036^{* * *}$ & $-0.055^{* * *}$ & $-0.106^{* * *}$ \\
\hline & $p$-value & 0.998 & 0.997 & 1.000 & 0.984 & 0.981 & 0.127 & 0.002 & 0.000 & 0.000 \\
\hline & Half-lives & $\infty$ & $\infty$ & $\infty$ & $\infty$ & $\infty$ & $\infty$ & 18.983 & 12.308 & 6.214 \\
\hline & $\mathrm{QKS} / p$-value & \multicolumn{9}{|c|}{$6.611(0.001)^{* * *}$} \\
\hline \multirow[t]{6}{*}{ Taiwan } & $\rho_{0}(\tau)$ & 0.194 & 0.128 & 0.049 & $0.288^{* * *}$ & $0.241^{* *}$ & $0.327^{* * *}$ & $0.438^{* * *}$ & $0.523^{* * *}$ & $0.698^{* * *}$ \\
\hline & $p$-value & 0.224 & 0.296 & 0.647 & 0.004 & 0.014 & 0.001 & 0.000 & 0.000 & 0.000 \\
\hline & $\rho_{1}(\tau)$ & -0.061 & -0.039 & -0.017 & $-0.064^{* *}$ & -0.051 & $-0.065^{* *}$ & $-0.086^{* * *}$ & $-0.099^{* * *}$ & $-0.130^{* * *}$ \\
\hline & $p$-value & 0.105 & 0.175 & 0.354 & 0.026 & 0.172 & 0.017 & 0.002 & 0.001 & 0.001 \\
\hline & Half-lives & $\infty$ & $\infty$ & $\infty$ & 10.517 & $\infty$ & 10.309 & 7.732 & 6.640 & 4.964 \\
\hline & QKS/p-value & \multicolumn{9}{|c|}{$4.208(0.016)^{* *}$} \\
\hline \multirow[t]{6}{*}{ Thailand } & $\rho_{0}(\tau)$ & $-0.230^{* * *}$ & -0.079 & -0.015 & 0.001 & $0.103^{* *}$ & $0.140^{* * *}$ & $0.208^{* * *}$ & $0.295^{* * *}$ & $0.393^{* * *}$ \\
\hline & $p$-value & 0.002 & 0.182 & 0.778 & 0.985 & 0.042 & 0.007 & 0.000 & 0.000 & 0.000 \\
\hline & $\rho_{1}(\tau)$ & 0.027 & 0.004 & -0.004 & -0.003 & -0.020 & $-0.025^{* *}$ & $-0.036^{* * *}$ & $-0.049^{* * *}$ & $-0.064^{* * *}$ \\
\hline & $p$-value & 0.815 & 0.652 & 0.469 & 0.638 & 0.162 & 0.041 & 0.002 & 0.000 & 0.000 \\
\hline & Half-lives & $\infty$ & $\infty$ & $\infty$ & $\infty$ & $\infty$ & 27.735 & 19.096 & 13.755 & 10.536 \\
\hline & QKS/p-value & \multicolumn{9}{|c|}{$3.836(0.027)^{* *}$} \\
\hline
\end{tabular}

Notes: All the $p$-values are calculated with the bootstrap method with 5000 replications. For $\hat{\rho}_{0}(\tau)$ the null of zero is tested with the student- $t$ test, while for $\hat{\rho}_{1}(\tau)$, the unit-root null is tested with the $t_{n}(\tau)$ statistic. ${ }^{* * *},{ }^{* *}$ and ${ }^{*}$ denote significance at the 1,5 and $10 \%$ levels. 
Table 4. Quantile ADF unit root results for the pre-Global Financial Crisis period

\begin{tabular}{|c|c|c|c|c|c|c|c|c|c|c|}
\hline Country & $\tau$ & 0.1 & 0.2 & 0.3 & 0.4 & 0.5 & 0.6 & 0.7 & 0.8 & 0.9 \\
\hline \multirow[t]{6}{*}{ Australia } & $\rho_{0}(\tau)$ & 0.010 & -0.011 & -0.027 & -0.013 & 0.039 & 0.014 & -0.006 & 0.086 & $0.138^{*}$ \\
\hline & $p$-value & 0.906 & 0.864 & 0.610 & 0.784 & 0.417 & 0.785 & 0.912 & 0.161 & 0.068 \\
\hline & $\rho_{1}(\tau)$ & -0.012 & -0.004 & 0.004 & 0.003 & -0.006 & 0.002 & 0.008 & -0.011 & -0.019 \\
\hline & $p$-value & 0.250 & 0.443 & 0.715 & 0.840 & 0.646 & 0.716 & 0.866 & 0.255 & 0.115 \\
\hline & Half-lives & $\infty$ & $\infty$ & $\infty$ & $\infty$ & $\infty$ & $\infty$ & $\infty$ & $\infty$ & $\infty$ \\
\hline & $\mathrm{QKS} / p$-value & \multicolumn{9}{|c|}{$1.154(0.527)$} \\
\hline \multirow[t]{6}{*}{ China } & $\rho_{0}(\tau)$ & $-0.225^{* * *}$ & $-0.113^{*}$ & -0.028 & 0.016 & 0.050 & 0.074 & $0.144^{* * *}$ & $0.297^{* * *}$ & $0.301^{* * *}$ \\
\hline & $p$-value & 0.003 & 0.067 & 0.623 & 0.767 & 0.334 & 0.150 & 0.007 & 0.000 & 0.000 \\
\hline & $\rho_{1}(\tau)$ & 0.029 & 0.012 & -0.004 & -0.008 & -0.011 & -0.012 & $-0.023^{*}$ & $-0.053^{* * *}$ & $-0.042^{* *}$ \\
\hline & $p$-value & 0.941 & 0.826 & 0.497 & 0.538 & 0.642 & 0.450 & 0.092 & 0.001 & 0.035 \\
\hline & Half-lives & $\infty$ & $\infty$ & $\infty$ & $\infty$ & $\infty$ & $\infty$ & 29.547 & 12.641 & 16.296 \\
\hline & $\mathrm{QKS} / p$-value & \multicolumn{9}{|c|}{$3.394(0.033)^{* *}$} \\
\hline \multirow[t]{6}{*}{ Hong Kong } & $\rho_{0}(\tau)$ & 0.161 & 0.142 & 0.059 & -0.008 & 0.026 & 0.101 & $0.220^{* *}$ & $0.277^{* *}$ & $0.479^{* * *}$ \\
\hline & $p$-value & 0.253 & 0.214 & 0.569 & 0.937 & 0.783 & 0.286 & 0.034 & 0.018 & 0.001 \\
\hline & $\rho_{1}(\tau)$ & -0.056 & $-0.044^{* * *}$ & -0.020 & 0.000 & -0.004 & -0.019 & -0.041 & $-0.049^{*}$ & $-0.089^{* * *}$ \\
\hline & $p$-value & 0.107 & 0.097 & 0.312 & 0.688 & 0.790 & 0.439 & 0.111 & 0.058 & 0.008 \\
\hline & Half-lives & $\infty$ & 15.533 & $\infty$ & $\infty$ & $\infty$ & $\infty$ & $\infty$ & 13.783 & 7.429 \\
\hline & QKS/p-value & \multicolumn{9}{|c|}{$2.753(0.123)$} \\
\hline \multirow[t]{6}{*}{ Indonesia } & $\rho_{0}(\tau)$ & -0.099 & -0.022 & -0.039 & -0.015 & 0.061 & 0.087 & $0.206^{* * *}$ & $0.209^{* * *}$ & $0.274^{* * *}$ \\
\hline & $p$-value & 0.246 & 0.753 & 0.531 & 0.796 & 0.510 & 0.144 & 0.001 & 0.003 & 0.002 \\
\hline & $\rho_{1}(\tau)$ & -0.003 & -0.011 & 0.000 & -0.001 & -0.014 & -0.016 & $-0.039^{* *}$ & $-0.034^{* *}$ & $-0.039^{* *}$ \\
\hline & $p$-value & 0.430 & 0.308 & 0.628 & 0.631 & 0.298 & 0.346 & 0.015 & 0.025 & 0.042 \\
\hline & Half-lives & $\infty$ & $\infty$ & $\infty$ & $\infty$ & $\infty$ & $\infty$ & 17.628 & 20.024 & 17.424 \\
\hline & $\mathrm{QKS} / p$-value & \multicolumn{9}{|c|}{$2.482(0.138)$} \\
\hline
\end{tabular}

Notes: See the notes for Table 3. 
Table 4. (Continued)

\begin{tabular}{|c|c|c|c|c|c|c|c|c|c|c|}
\hline Country & $\tau$ & 0.1 & 0.2 & 0.3 & 0.4 & 0.5 & 0.6 & 0.7 & 0.8 & 0.9 \\
\hline \multirow[t]{6}{*}{ Japan } & $\rho_{0}(\tau)$ & 0.082 & 0.115 & 0.111 & 0.128 & 0.142 & $0.173^{*}$ & $0.261^{* *}$ & $0.281^{* *}$ & $0.367^{* *}$ \\
\hline & $p$-value & 0.589 & 0.331 & 0.289 & 0.180 & 0.126 & 0.071 & 0.011 & 0.015 & 0.015 \\
\hline & $\rho_{1}(\tau)$ & -0.030 & -0.031 & -0.027 & -0.028 & -0.028 & -0.032 & $-0.047^{* *}$ & $-0.048^{* *}$ & $-0.060^{* *}$ \\
\hline & $p$-value & 0.164 & 0.182 & 0.194 & 0.220 & 0.358 & 0.120 & 0.030 & 0.023 & 0.015 \\
\hline & Half-lives & $\infty$ & $\infty$ & $\infty$ & $\infty$ & $\infty$ & $\infty$ & 14.265 & 13.943 & 11.132 \\
\hline & QKS/p-value & \multicolumn{9}{|c|}{$2.349(0.104)$} \\
\hline \multirow[t]{6}{*}{ Malaysia } & $\rho_{0}(\tau)$ & -0.229 & 0.072 & 0.070 & $0.190^{*}$ & $0.243^{* *}$ & $0.239^{* *}$ & $0.272^{* * *}$ & $0.389^{* * *}$ & $0.687^{* * *}$ \\
\hline & $p$-value & 0.112 & 0.514 & 0.490 & 0.051 & 0.011 & 0.014 & 0.009 & 0.001 & 0.000 \\
\hline & $\rho_{1}(\tau)$ & 0.032 & -0.027 & -0.023 & $-0.046^{*}$ & -0.054 & $-0.050^{*}$ & $-0.053^{* *}$ & $-0.076^{* *}$ & $-0.135^{* * *}$ \\
\hline & $p$-value & 0.775 & 0.204 & 0.215 & 0.091 & 0.102 & 0.060 & 0.025 & 0.010 & 0.001 \\
\hline & Half-lives & $\infty$ & $\infty$ & $\infty$ & 14.596 & $\infty$ & 13.454 & 12.611 & 8.808 & 4.766 \\
\hline & QKS/p-value & \multicolumn{9}{|c|}{$4.144(0.006)^{* * *}$} \\
\hline \multirow[t]{6}{*}{ New Zealand } & $\rho_{0}(\tau)$ & 0.006 & 0.111 & 0.122 & $0.300^{* * *}$ & $0.389^{* * *}$ & $0.243^{* *}$ & $0.274^{* *}$ & $0.364^{* * *}$ & $0.460^{* * *}$ \\
\hline & $p$-value & 0.966 & 0.366 & 0.238 & 0.002 & 0.000 & 0.013 & 0.010 & 0.002 & 0.002 \\
\hline & $\rho_{1}(\tau)$ & -0.011 & -0.029 & -0.028 & $-0.062^{* *}$ & $-0.078^{* * *}$ & $-0.046^{* *}$ & $-0.051^{* * *}$ & $-0.067^{* * *}$ & $-0.082^{* * *}$ \\
\hline & $p$-value & 0.357 & 0.228 & 0.250 & 0.026 & 0.004 & 0.047 & 0.008 & 0.003 & 0.006 \\
\hline & Half-lives & $\infty$ & $\infty$ & $\infty$ & 10.871 & 8.511 & 14.577 & 13.330 & 9.954 & 8.060 \\
\hline & QKS/p-value & \multicolumn{9}{|c|}{$4.073(0.015)^{* *}$} \\
\hline \multirow[t]{6}{*}{ Philippines } & $\rho_{0}(\tau)$ & 0.112 & -0.021 & -0.009 & 0.061 & 0.036 & 0.038 & 0.097 & $0.165^{* *}$ & $0.199^{* *}$ \\
\hline & $p$-value & 0.218 & 0.778 & 0.893 & 0.298 & 0.780 & 0.516 & 0.126 & 0.022 & 0.028 \\
\hline & $\rho_{1}(\tau)$ & -0.044 & -0.009 & -0.007 & -0.016 & -0.007 & -0.004 & -0.011 & -0.021 & -0.020 \\
\hline & $p$-value & 0.008 & 0.313 & 0.410 & 0.309 & 0.780 & 0.677 & 0.339 & 0.133 & 0.141 \\
\hline & Half-lives & 15.461 & $\infty$ & $\infty$ & $\infty$ & $\infty$ & $\infty$ & $\infty$ & $\infty$ & $\infty$ \\
\hline & QKS/p-value & \multicolumn{9}{|c|}{$2.345(0.126)$} \\
\hline
\end{tabular}

Notes: See the notes for Table 3. 
Table 4. (Continued)

\begin{tabular}{|c|c|c|c|c|c|c|c|c|c|c|}
\hline Country & $\tau$ & 0.1 & 0.2 & 0.3 & 0.4 & 0.5 & 0.6 & 0.7 & 0.8 & 0.9 \\
\hline \multirow[t]{6}{*}{ Singapore } & $\rho_{0}(\tau)$ & 0.102 & 0.039 & 0.051 & 0.081 & 0.118 & $0.203^{* *}$ & 0.123 & $0.211^{* *}$ & $0.284^{* *}$ \\
\hline & $p$-value & 0.397 & 0.700 & 0.565 & 0.347 & 0.161 & 0.020 & 0.175 & 0.040 & 0.023 \\
\hline & $\rho_{1}(\tau)$ & -0.037 & -0.018 & -0.016 & -0.020 & -0.026 & $-0.042^{*}$ & -0.021 & -0.037 & -0.048 \\
\hline & $p$-value & 0.202 & 0.319 & 0.355 & 0.406 & 0.417 & 0.097 & 0.280 & 0.130 & 0.128 \\
\hline & Half-lives & $\infty$ & $\infty$ & $\infty$ & $\infty$ & $\infty$ & 16.352 & $\infty$ & $\infty$ & $\infty$ \\
\hline & $\mathrm{QKS} / p$-value & \multicolumn{9}{|c|}{$2.134(0.262)$} \\
\hline \multirow[t]{6}{*}{ South Korea } & $\rho_{0}(\tau)$ & $-0.438^{* * *}$ & $-0.242^{* *}$ & $-0.145^{*}$ & -0.098 & -0.016 & 0.094 & $0.225^{* * *}$ & $0.328^{* * *}$ & $0.583^{* * *}$ \\
\hline & $p$-value & 0.000 & 0.013 & 0.095 & 0.220 & 0.834 & 0.224 & 0.008 & 0.001 & 0.000 \\
\hline & $\rho_{1}(\tau)$ & 0.085 & 0.045 & 0.025 & 0.019 & 0.004 & -0.018 & $-0.044^{*}$ & $-0.064^{* *}$ & $-0.115^{* * *}$ \\
\hline & $p$-value & 0.999 & 0.983 & 0.951 & 0.962 & 0.942 & 0.414 & 0.060 & 0.012 & 0.000 \\
\hline & Half-lives & $\infty$ & $\infty$ & $\infty$ & $\infty$ & $\infty$ & $\infty$ & 15.257 & 10.469 & 5.649 \\
\hline & $\mathrm{QKS} / p$-value & \multicolumn{9}{|c|}{$3.704(0.030)^{* *}$} \\
\hline \multirow[t]{6}{*}{ Taiwan } & $\rho_{0}(\tau)$ & 0.230 & 0.179 & 0.202 & $0.255^{*}$ & $0.306^{* *}$ & $0.295^{* *}$ & $0.333^{* *}$ & $0.595^{* * *}$ & $0.633^{* * *}$ \\
\hline & $p$-value & 0.276 & 0.281 & 0.166 & 0.057 & 0.019 & 0.026 & 0.022 & 0.000 & 0.003 \\
\hline & $\rho_{1}(\tau)$ & $-0.071^{*}$ & $-0.052^{*}$ & -0.051 & $-0.058^{*}$ & -0.066 & -0.059 & -0.061 & $-0.112^{* *}$ & $-0.112^{* *}$ \\
\hline & $p$-value & 0.054 & 0.094 & 0.102 & 0.094 & 0.200 & 0.255 & 0.143 & 0.013 & 0.036 \\
\hline & Half-lives & 9.387 & 12.979 & $\infty$ & 11.594 & $\infty$ & $\infty$ & $\infty$ & 5.863 & 5.861 \\
\hline & QKS/p-value & \multicolumn{9}{|c|}{$3.158(0.060)^{*}$} \\
\hline \multirow[t]{6}{*}{ Thailand } & $\rho_{0}(\tau)$ & $-0.233^{* *}$ & 0.018 & 0.010 & 0.034 & 0.057 & 0.095 & $0.183^{* * *}$ & $0.265^{* * *}$ & $0.240^{* * *}$ \\
\hline & $p$-value & 0.015 & 0.807 & 0.877 & 0.591 & 0.357 & 0.132 & 0.006 & 0.000 & 0.008 \\
\hline & $\rho_{1}(\tau)$ & 0.022 & -0.019 & -0.010 & -0.012 & -0.013 & -0.017 & $-0.030^{*}$ & $-0.042^{* *}$ & -0.027 \\
\hline & $p$-value & 0.727 & 0.231 & 0.338 & 0.351 & 0.549 & 0.336 & 0.052 & 0.012 & 0.192 \\
\hline & Half-lives & $\infty$ & $\infty$ & $\infty$ & $\infty$ & $\infty$ & $\infty$ & 22.651 & 16.107 & $\infty$ \\
\hline & QKS/p-value & \multicolumn{9}{|c|}{$2.735(0.157)$} \\
\hline
\end{tabular}

Notes: See the notes for Table 3. 
Table 5. Quantile ADF unit root results for the post-Global Financial Crisis period

\begin{tabular}{|c|c|c|c|c|c|c|c|c|c|c|}
\hline Country & $\tau$ & 0.1 & 0.2 & 0.3 & 0.4 & 0.5 & 0.6 & 0.7 & 0.8 & 0.9 \\
\hline \multirow[t]{6}{*}{ Australia } & $\rho_{0}(\tau)$ & 0.086 & $0.455^{*}$ & $0.548^{* *}$ & $0.660^{* * *}$ & $0.566^{* * *}$ & $0.470^{* *}$ & $0.777^{* * *}$ & $0.868^{* * *}$ & $0.961^{* * *}$ \\
\hline & $p$-value & 0.785 & 0.074 & 0.010 & 0.001 & 0.004 & 0.023 & 0.001 & 0.001 & 0.001 \\
\hline & $\rho_{1}(\tau)$ & -0.028 & $-0.104^{*}$ & $-0.121^{* *}$ & $-0.142^{* *}$ & $-0.120^{*}$ & $-0.098^{* *}$ & $-0.162^{* * *}$ & $-0.179^{* * *}$ & $-0.198^{* * *}$ \\
\hline & $p$-value & 0.358 & 0.052 & 0.028 & 0.010 & 0.062 & 0.022 & 0.000 & 0.003 & 0.001 \\
\hline & Half-lives & $\infty$ & 6.296 & 5.374 & 4.511 & 5.422 & 6.734 & 3.929 & 3.515 & 3.148 \\
\hline & $\mathrm{QKS} / p$-value & \multicolumn{9}{|c|}{$3.418(0.035)^{* *}$} \\
\hline \multirow[t]{6}{*}{ China } & $\rho_{0}(\tau)$ & $0.737^{* * *}$ & $0.656^{* * *}$ & 0.196 & 0.278 & 0.229 & 0.133 & 0.170 & 0.244 & 0.090 \\
\hline & $p$-value & 0.006 & 0.003 & 0.269 & 0.107 & 0.177 & 0.446 & 0.355 & 0.228 & 0.739 \\
\hline & $\rho_{1}(\tau)$ & $-0.176^{* * *}$ & $-0.153^{* * *}$ & -0.047 & -0.062 & -0.048 & -0.024 & -0.029 & -0.042 & 0.000 \\
\hline & $p$-value & 0.006 & 0.008 & 0.364 & 0.313 & 0.383 & 0.405 & 0.335 & 0.237 & 0.549 \\
\hline & Half-lives & 3.587 & 4.178 & $\infty$ & $\infty$ & $\infty$ & $\infty$ & $\infty$ & $\infty$ & $\infty$ \\
\hline & $\mathrm{QKS} / p$-value & \multicolumn{9}{|c|}{$3.271(0.030)^{* *}$} \\
\hline \multirow[t]{6}{*}{ Hong Kong } & $\rho_{0}(\tau)$ & -0.079 & -0.039 & $0.584^{* * *}$ & $0.528^{* * *}$ & $0.494^{* *}$ & $0.728^{* * *}$ & $0.957^{* * *}$ & $1.137^{* * *}$ & $1.035^{* * *}$ \\
\hline & $p$-value & 0.786 & 0.868 & 0.003 & 0.006 & 0.011 & 0.000 & 0.000 & 0.000 & 0.000 \\
\hline & $\rho_{1}(\tau)$ & 0.005 & 0.002 & $-0.124^{* * *}$ & $-0.110^{*}$ & $-0.101^{* *}$ & $-0.148^{* * *}$ & $-0.193^{* * *}$ & $-0.228^{* * *}$ & $-0.205^{* * *}$ \\
\hline & $p$-value & 0.602 & 0.633 & 0.002 & 0.050 & 0.047 & 0.000 & 0.000 & 0.001 & 0.000 \\
\hline & Half-lives & $\infty$ & $\infty$ & 5.240 & 5.945 & 6.497 & 4.332 & 3.230 & 2.677 & 3.029 \\
\hline & $\mathrm{QKS} / p$-value & \multicolumn{9}{|c|}{$4.506(0.004)^{* * *}$} \\
\hline \multirow[t]{6}{*}{ Indonesia } & $\rho_{0}(\tau)$ & 0.180 & 0.174 & $0.749^{* * *}$ & $1.001^{* * *}$ & $1.019^{* * *}$ & $0.974^{* * *}$ & $0.961^{* * *}$ & $0.951^{* * *}$ & $1.057^{* * *}$ \\
\hline & $p$-value & 0.467 & 0.337 & 0.000 & 0.000 & 0.000 & 0.000 & 0.000 & 0.000 & 0.000 \\
\hline & $\rho_{1}(\tau)$ & -0.053 & -0.044 & $-0.160^{* * *}$ & $-0.210^{* * *}$ & $-0.211^{* * *}$ & $-0.200^{* * *}$ & $-0.195^{* * *}$ & $-0.191^{* * *}$ & $-0.208^{* * *}$ \\
\hline & $p$-value & 0.260 & 0.236 & 0.000 & 0.000 & 0.000 & 0.000 & 0.000 & 0.000 & 0.000 \\
\hline & Half-lives & $\infty$ & $\infty$ & 3.983 & 2.935 & 2.925 & 3.109 & 3.192 & 3.265 & 2.965 \\
\hline & $\mathrm{QKS} / p$-value & \multicolumn{9}{|c|}{$7.232(0.000)^{* * *}$} \\
\hline
\end{tabular}


Table 5. (Continued)

\begin{tabular}{|c|c|c|c|c|c|c|c|c|c|c|}
\hline Country & $\tau$ & 0.1 & 0.2 & 0.3 & 0.4 & 0.5 & 0.6 & 0.7 & 0.8 & 0.9 \\
\hline \multirow[t]{6}{*}{ Japan } & $\rho_{0}(\tau)$ & 0.002 & -0.075 & -0.049 & 0.057 & 0.100 & 0.108 & 0.094 & $0.311^{* *}$ & $0.337^{* *}$ \\
\hline & $p$-value & 0.989 & 0.498 & 0.619 & 0.528 & 0.268 & 0.246 & 0.366 & 0.012 & 0.021 \\
\hline & $\rho_{1}(\tau)$ & -0.014 & 0.009 & 0.007 & -0.012 & -0.019 & -0.018 & -0.012 & $-0.054^{*}$ & $-0.056^{* *}$ \\
\hline & $p$-value & 0.353 & 0.680 & 0.771 & 0.595 & 0.523 & 0.399 & 0.416 & 0.052 & 0.027 \\
\hline & Half-lives & $\infty$ & $\infty$ & $\infty$ & $\infty$ & $\infty$ & $\infty$ & $\infty$ & 12.563 & 12.138 \\
\hline & QKS/p-value & \multicolumn{9}{|c|}{$2.123(0.255)$} \\
\hline \multirow[t]{6}{*}{ Malaysia } & $\rho_{0}(\tau)$ & 0.285 & $0.319^{* *}$ & $0.257^{* *}$ & $0.332^{* * *}$ & $0.305^{* * *}$ & $0.410^{* * *}$ & $0.472^{* * *}$ & $0.569^{* * *}$ & $0.813^{* * *}$ \\
\hline & $p$-value & 0.146 & 0.018 & 0.035 & 0.003 & 0.007 & 0.000 & 0.000 & 0.000 & 0.000 \\
\hline & $\rho_{1}(\tau)$ & $-0.068^{*}$ & $-0.071^{* *}$ & -0.056 & $-0.070^{*}$ & $-0.064^{*}$ & $-0.085^{* * *}$ & $-0.096^{* * *}$ & $-0.116^{* * *}$ & $-0.164^{* * *}$ \\
\hline & $p$-value & 0.064 & 0.042 & 0.113 & 0.054 & 0.097 & 0.004 & 0.000 & 0.000 & 0.000 \\
\hline & Half-lives & 9.791 & 9.432 & $\infty$ & 9.494 & 10.560 & 7.794 & 6.872 & 5.643 & 3.861 \\
\hline & QKS/p-value & \multicolumn{9}{|c|}{$4.319(0.001)^{* * *}$} \\
\hline \multirow[t]{6}{*}{ New Zealand } & $\rho_{0}(\tau)$ & -0.016 & 0.069 & 0.007 & 0.039 & 0.064 & 0.042 & 0.076 & 0.081 & 0.110 \\
\hline & $p$-value & 0.845 & 0.301 & 0.908 & 0.497 & 0.263 & 0.482 & 0.235 & 0.242 & 0.168 \\
\hline & $\rho_{1}(\tau)$ & -0.002 & -0.017 & -0.003 & -0.008 & -0.012 & -0.006 & -0.012 & -0.012 & -0.016 \\
\hline & $p$-value & 0.436 & 0.255 & 0.520 & 0.489 & 0.518 & 0.544 & 0.253 & 0.237 & 0.154 \\
\hline & Half-lives & $\infty$ & $\infty$ & $\infty$ & $\infty$ & $\infty$ & $\infty$ & $\infty$ & $\infty$ & $\infty$ \\
\hline & QKS/p-value & \multicolumn{9}{|c|}{$1.228(0.453)$} \\
\hline \multirow[t]{6}{*}{ Philippines } & $\rho_{0}(\tau)$ & 0.025 & 0.129 & 0.150 & $0.153^{*}$ & $0.257^{* * *}$ & $0.261^{* * *}$ & $0.310^{* * *}$ & $0.327^{* * *}$ & $0.727^{* *}$ \\
\hline & $p$-value & 0.854 & 0.221 & 0.110 & 0.076 & 0.002 & 0.003 & 0.001 & 0.002 & 0.000 \\
\hline & $\rho_{1}(\tau)$ & -0.016 & -0.032 & -0.034 & -0.031 & $-0.050^{* *}$ & $-0.048^{* *}$ & $-0.057^{* * *}$ & $-0.057^{* * *}$ & $-0.132^{* * *}$ \\
\hline & $p$-value & 0.440 & 0.217 & 0.211 & 0.223 & 0.017 & 0.021 & 0.002 & 0.000 & 0.000 \\
\hline & Half-lives & $\infty$ & $\infty$ & $\infty$ & $\infty$ & 13.636 & 13.946 & 11.837 & 11.810 & 4.906 \\
\hline & QKS/p-value & \multicolumn{9}{|c|}{$4.440(0.037)^{* *}$} \\
\hline
\end{tabular}

Notes: See the notes for Table 3. 
Table 5. (Continued)

\begin{tabular}{|c|c|c|c|c|c|c|c|c|c|c|}
\hline Country & $\tau$ & 0.1 & 0.2 & 0.3 & 0.4 & 0.5 & 0.6 & 0.7 & 0.8 & 0.9 \\
\hline \multirow[t]{5}{*}{ Singapore } & $\rho_{0}(\tau)$ & -0.453 & 0.274 & $0.457^{* *}$ & $0.488^{* *}$ & $0.513^{* * *}$ & $0.822^{* * *}$ & $0.857^{* * *}$ & $1.011^{* * *}$ & $0.881^{* * *}$ \\
\hline & $p$-value & 0.183 & 0.235 & 0.019 & 0.011 & 0.008 & 0.000 & 0.000 & 0.000 & 0.000 \\
\hline & $\rho_{1}(\tau)$ & 0.085 & -0.066 & $-0.102^{*}$ & $-0.106^{*}$ & $-0.110^{* *}$ & $-0.176^{* * *}$ & $-0.181^{* * *}$ & $-0.213^{* * *}$ & $-0.183^{* * *}$ \\
\hline & Half-lives & $\infty$ & $\infty$ & 6.466 & 6.172 & 5.930 & 3.588 & 3.472 & 2.894 & 3.432 \\
\hline & QKS/p-value & \multicolumn{9}{|c|}{$4.370(0.007)^{* * *}$} \\
\hline \multirow{4}{*}{ South Korea } & $\rho_{1}(\tau)$ & $-0.085^{*}$ & $-0.107^{* * *}$ & $-0.107^{* *}$ & $-0.120^{* * *}$ & $-0.125^{* *}$ & $-0.113^{* *}$ & $-0.102^{* *}$ & $-0.143^{* * *}$ & $-0.149^{* * *}$ \\
\hline & $p$-value & 0.079 & 0.008 & 0.023 & 0.009 & 0.018 & 0.014 & 0.022 & 0.006 & 0.003 \\
\hline & Half-lives & 7.772 & 6.103 & 6.104 & 5.444 & 5.177 & 5.763 & 6.458 & 4.496 & 4.295 \\
\hline & QKS/p-value & \multicolumn{9}{|c|}{$3.806(0.015)^{* *}$} \\
\hline \multirow[t]{2}{*}{ Taiwan } & $\rho_{0}(\tau)$ & -0.268 & -0.017 & 0.239 & $0.448^{* * *}$ & $0.316^{* *}$ & $0.463^{* * *}$ & $0.604^{* * *}$ & $0.845^{* * *}$ & $0.934^{* * *}$ \\
\hline & QKS/p-value & \multicolumn{9}{|c|}{$4.466(0.035)^{* *}$} \\
\hline \multirow[t]{6}{*}{ Thailand } & $\rho_{0}(\tau)$ & 0.232 & $0.231^{*}$ & $0.407^{* * *}$ & $0.440^{* * *}$ & $0.525^{* * *}$ & $0.601^{* * *}$ & $0.723^{* * *}$ & $0.719^{* * *}$ & $0.771^{* * *}$ \\
\hline & $p$-value & 0.215 & 0.087 & 0.000 & 0.000 & 0.000 & 0.000 & 0.000 & 0.000 & 0.000 \\
\hline & $\rho_{1}(\tau)$ & -0.058 & -0.051 & $-0.083^{* * *}$ & $-0.087^{* * *}$ & $-0.103^{* * *}$ & $-0.116^{* * *}$ & $-0.138^{* *}$ & $-0.136^{* * *}$ & $-0.142^{* *}$ \\
\hline & $p$-value & 0.188 & 0.163 & 0.002 & 0.001 & 0.000 & 0.000 & 0.011 & 0.000 & 0.013 \\
\hline & Half-lives & $\infty$ & $\infty$ & 8.031 & 7.587 & 6.403 & 5.616 & 4.671 & 4.754 & 4.511 \\
\hline & QKS/p-value & \multicolumn{9}{|c|}{$5.348(0.002)^{* * *}$} \\
\hline
\end{tabular}

Notes: See the notes for Table 3. 
Table 6. Quantile ADF unit root results with structural break

\begin{tabular}{|c|c|c|c|c|c|c|c|c|c|c|}
\hline Country & $\tau$ & 0.1 & 0.2 & 0.3 & 0.4 & 0.5 & 0.6 & 0.7 & 0.8 & 0.9 \\
\hline \multirow[t]{6}{*}{ Australia } & $\rho_{0}(\tau)$ & $-0.051^{* * *}$ & $-0.033^{* * *}$ & $-0.016^{* * *}$ & -0.002 & $0.009^{* * *}$ & $0.018^{* * *}$ & $0.027^{* * *}$ & $0.037^{* * *}$ & $0.048^{* * *}$ \\
\hline & $p$-value & 0.000 & 0.000 & 0.000 & 0.430 & 0.001 & 0.000 & 0.000 & 0.000 & 0.000 \\
\hline & $\rho_{1}(\tau)$ & -0.011 & 0.000 & -0.015 & -0.012 & -0.009 & -0.015 & -0.015 & $-0.031^{* *}$ & $-0.036^{* * *}$ \\
\hline & $p$-value & 0.321 & 0.503 & 0.239 & 0.487 & 0.429 & 0.156 & 0.127 & 0.015 & 0.009 \\
\hline & Half-lives & $\infty$ & $\infty$ & $\infty$ & $\infty$ & $\infty$ & $\infty$ & $\infty$ & 21.790 & 18.789 \\
\hline & QKS/p-value & \multicolumn{9}{|c|}{$2.157(0.192)$} \\
\hline \multirow[t]{6}{*}{ China } & $\rho_{0}(\tau)$ & $-0.115^{* * *}$ & $-0.066^{* * *}$ & $-0.036^{* * *}$ & -0.011 & 0.009 & $0.029^{* * *}$ & $0.057^{* * *}$ & $0.080^{* * *}$ & $0.126^{* * *}$ \\
\hline & $p$-value & 0.000 & 0.000 & 0.000 & 0.157 & 0.255 & 0.000 & 0.000 & 0.000 & 0.000 \\
\hline & $\rho_{1}(\tau)$ & 0.012 & 0.010 & 0.006 & -0.006 & -0.010 & $-0.019^{*}$ & $-0.039^{* * *}$ & $-0.055^{* * *}$ & $-0.052^{* * *}$ \\
\hline & $p$-value & 0.727 & 0.833 & 0.796 & 0.465 & 0.402 & 0.065 & 0.004 & 0.000 & 0.000 \\
\hline & Half-lives & $\infty$ & $\infty$ & $\infty$ & $\infty$ & $\infty$ & 36.583 & 17.605 & 12.350 & 12.971 \\
\hline & QKS/p-value & \multicolumn{9}{|c|}{$4.652(0.014)^{* *}$} \\
\hline \multirow[t]{6}{*}{ Hong Kong } & $\rho_{0}(\tau)$ & $-0.084^{* * *}$ & $-0.046^{* * *}$ & $-0.024^{* * *}$ & $-0.009^{* *}$ & 0.004 & $0.018^{* * *}$ & $0.038^{* * *}$ & $0.058^{* * *}$ & $0.089^{* * *}$ \\
\hline & $p$-value & 0.000 & 0.000 & 0.000 & 0.043 & 0.284 & 0.000 & 0.000 & 0.000 & 0.000 \\
\hline & $\rho_{1}(\tau)$ & -0.013 & 0.009 & 0.004 & -0.002 & -0.009 & -0.024 & $-0.055^{* * *}$ & $-0.070^{* * *}$ & $-0.117^{* * *}$ \\
\hline & $p$-value & 0.346 & 0.723 & 0.661 & 0.619 & 0.530 & 0.131 & 0.005 & 0.000 & 0.000 \\
\hline & Half-lives & $\infty$ & $\infty$ & $\infty$ & $\infty$ & $\infty$ & $\infty$ & 12.239 & 9.482 & 5.567 \\
\hline & QKS/p-value & \multicolumn{9}{|c|}{$5.435(0.003)^{* * *}$} \\
\hline \multirow[t]{6}{*}{ Indonesia } & $\rho_{0}(\tau)$ & $-0.099^{* * *}$ & $-0.059^{* * *}$ & $-0.030^{* * *}$ & $-0.019^{* * *}$ & 0.006 & $0.023^{* * *}$ & $0.044^{* * *}$ & $0.059^{* * *}$ & $0.101^{* * *}$ \\
\hline & $p$-value & 0.000 & 0.000 & 0.000 & 0.001 & 0.260 & 0.000 & 0.000 & 0.000 & 0.000 \\
\hline & $\rho_{1}(\tau)$ & 0.010 & 0.013 & 0.009 & 0.009 & -0.005 & $-0.027^{* *}$ & $-0.040^{* * *}$ & $-0.045^{* * *}$ & $-0.069^{* * *}$ \\
\hline & $p$-value & 0.719 & 0.822 & 0.865 & 0.894 & 0.611 & 0.023 & 0.001 & 0.000 & 0.000 \\
\hline & Half-lives & $\infty$ & $\infty$ & $\infty$ & $\infty$ & $\infty$ & 25.379 & 16.956 & 15.002 & 9.679 \\
\hline & QKS/p-value & \multicolumn{9}{|c|}{$4.732(0.011)^{* *}$} \\
\hline
\end{tabular}

Notes: See the notes for Table 3. 
Table 6. (Continued)

\begin{tabular}{|c|c|c|c|c|c|c|c|c|c|c|}
\hline Country & $\tau$ & 0.1 & 0.2 & 0.3 & 0.4 & 0.5 & 0.6 & 0.7 & 0.8 & 0.9 \\
\hline \multirow[t]{6}{*}{ Japan } & $\rho_{0}(\tau)$ & $-0.072^{* * *}$ & $-0.038^{* * *}$ & $-0.022^{* * *}$ & $-0.009^{* *}$ & 0.005 & $0.016^{* * *}$ & $0.029^{* * *}$ & $0.044^{* * *}$ & $0.071^{* * *}$ \\
\hline & $p$-value & 0.000 & 0.000 & 0.000 & 0.020 & 0.175 & 0.000 & 0.000 & 0.000 & 0.000 \\
\hline & $\rho_{1}(\tau)$ & 0.068 & 0.005 & 0.020 & -0.012 & $-0.035^{*}$ & $-0.044^{* *}$ & $-0.067^{* * *}$ & $-0.085^{* * *}$ & $-0.147^{* * *}$ \\
\hline & $p$-value & 0.992 & 0.645 & 0.965 & 0.363 & 0.068 & 0.018 & 0.002 & 0.000 & 0.000 \\
\hline & Half-lives & $\infty$ & $\infty$ & $\infty$ & $\infty$ & 19.190 & 15.482 & 10.065 & 7.796 & 4.373 \\
\hline & QKS/p-value & \multicolumn{9}{|c|}{$7.053(0.000)^{* * *}$} \\
\hline \multirow[t]{6}{*}{ Malaysia } & $\rho_{0}(\tau)$ & $-0.065^{* * *}$ & $-0.040^{* * *}$ & $-0.019^{* * *}$ & $-0.006^{*}$ & 0.005 & $0.016^{* * *}$ & $0.027^{* * *}$ & $0.042^{* * *}$ & $0.063^{* * *}$ \\
\hline & $p$-value & 0.000 & 0.000 & 0.000 & 0.076 & 0.167 & 0.000 & 0.000 & 0.000 & 0.000 \\
\hline & $\rho_{1}(\tau)$ & -0.045 & -0.014 & -0.006 & -0.020 & $-0.036^{*}$ & $-0.047^{* *}$ & $-0.042^{* *}$ & $-0.063^{* * *}$ & $-0.084^{* * *}$ \\
\hline & $p$-value & 0.121 & 0.326 & 0.458 & 0.294 & 0.082 & 0.014 & 0.019 & 0.002 & 0.006 \\
\hline & Half-lives & $\infty$ & $\infty$ & $\infty$ & $\infty$ & 19.093 & 14.377 & 16.313 & 10.618 & 7.880 \\
\hline & QKS/p-value & \multicolumn{9}{|c|}{$3.618(0.041)^{* *}$} \\
\hline \multirow[t]{6}{*}{ New Zealand } & $\rho_{0}(\tau)$ & $-0.045^{* * *}$ & $-0.027^{* * *}$ & $-0.013^{* * *}$ & -0.003 & $0.005^{* *}$ & $0.014^{* * *}$ & $0.021^{* * *}$ & $0.029^{* * *}$ & $0.045^{* * *}$ \\
\hline & $p$-value & 0.000 & 0.000 & 0.000 & 0.125 & 0.012 & 0.000 & 0.000 & 0.000 & 0.000 \\
\hline & $\rho_{1}(\tau)$ & -0.024 & -0.013 & -0.021 & -0.024 & -0.027 & -0.020 & $-0.020^{* *}$ & $-0.028^{* *}$ & $-0.056^{* * *}$ \\
\hline & $p$-value & 0.225 & 0.324 & 0.185 & 0.173 & 0.150 & 0.105 & 0.046 & 0.017 & 0.008 \\
\hline & Half-lives & $\infty$ & $\infty$ & $\infty$ & $\infty$ & $\infty$ & $\infty$ & 33.860 & 24.031 & 12.051 \\
\hline & QKS/p-value & \multicolumn{9}{|c|}{$3.178(0.086)^{*}$} \\
\hline \multirow[t]{6}{*}{ Philippines } & $\rho_{0}(\tau)$ & $-0.089^{* * *}$ & $-0.053^{* * *}$ & $-0.032^{* * *}$ & $-0.014^{* *}$ & 0.005 & $0.020^{* * *}$ & $0.038^{* * *}$ & $0.058^{* * *}$ & $0.085^{* * *}$ \\
\hline & $p$-value & 0.000 & 0.000 & 0.000 & 0.001 & 0.232 & 0.000 & 0.000 & 0.000 & 0.000 \\
\hline & $\rho_{1}(\tau)$ & -0.011 & -0.011 & -0.014 & -0.010 & -0.009 & -0.010 & -0.017 & $-0.033^{* * *}$ & $-0.036^{* *}$ \\
\hline & $p$-value & 0.312 & 0.281 & 0.224 & 0.415 & 0.610 & 0.332 & 0.106 & 0.008 & 0.019 \\
\hline & Half-lives & $\infty$ & $\infty$ & $\infty$ & $\infty$ & $\infty$ & $\infty$ & $\infty$ & 20.951 & 18.971 \\
\hline & QKS/p-value & \multicolumn{9}{|c|}{$2.667(0.123)$} \\
\hline
\end{tabular}

Notes: See the notes for Table 3. 
Table 6. (Continued)

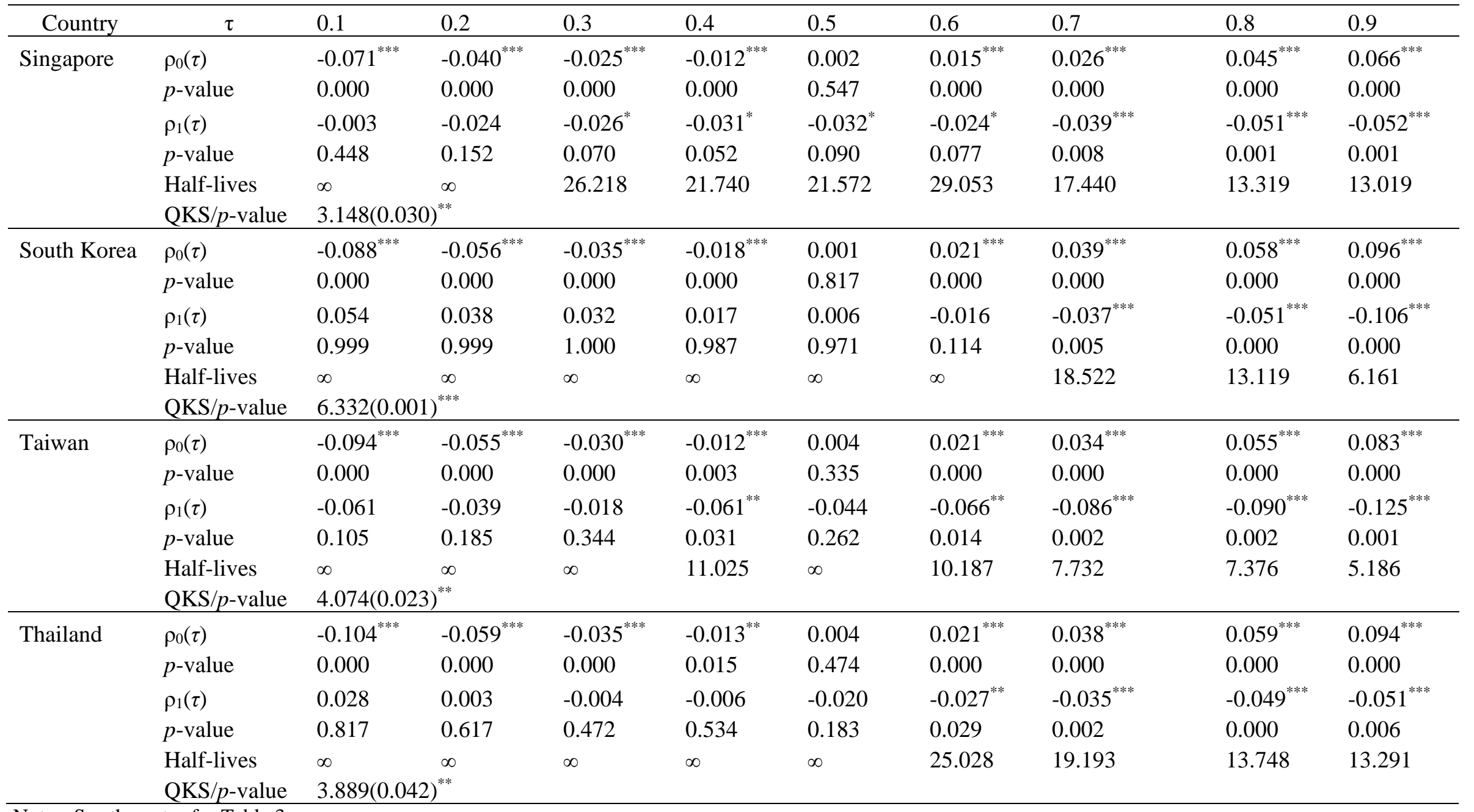

Notes: See the notes for Table 3. 
Figure 1. Real stock price indices in 12 Asia-Pacific countries
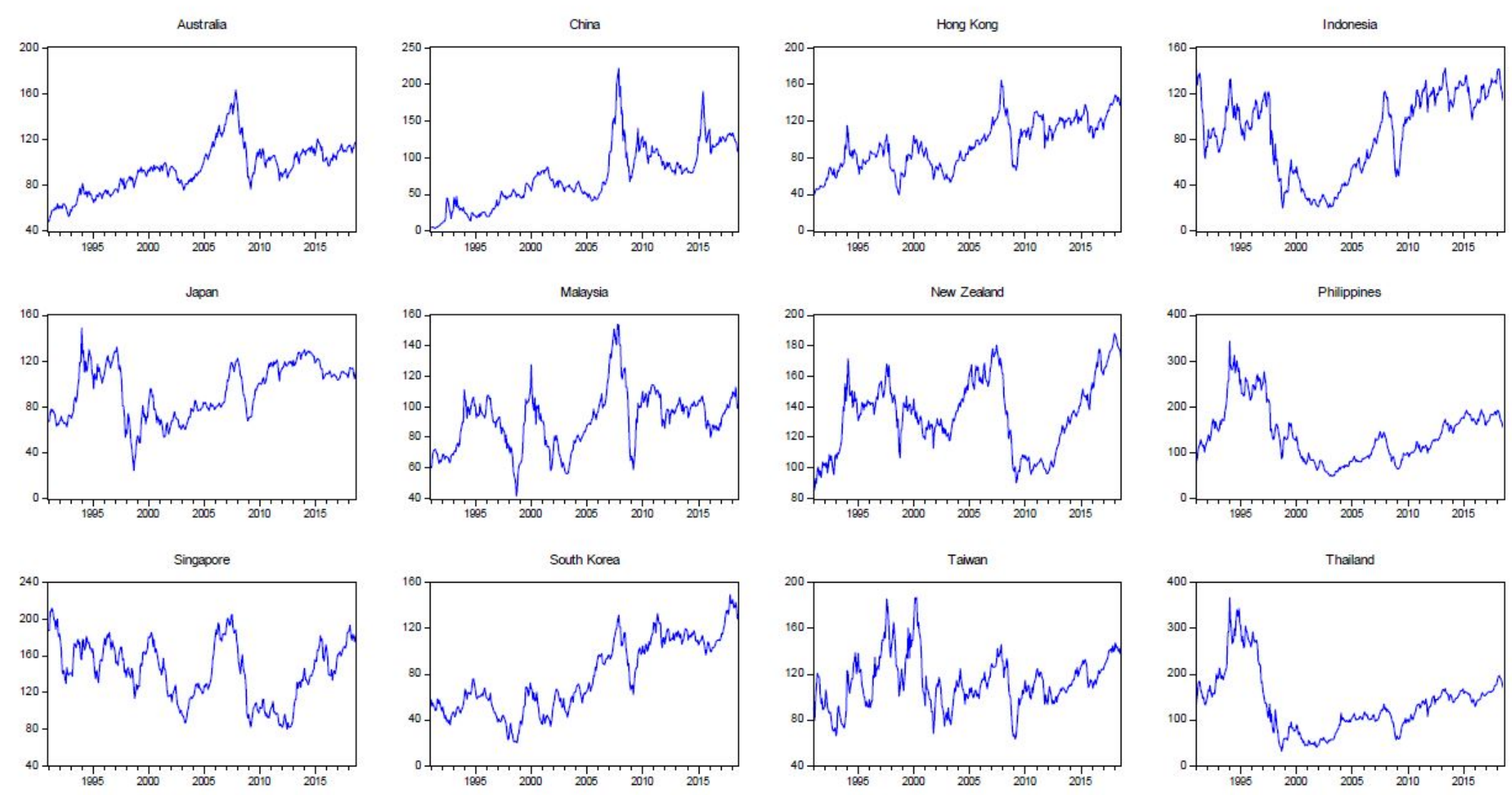
Figure 2. Quantile intercepts (rho 0), autoregressive coefficients (rho 1). Notes: The dashed lines signify the $95 \%$ confidence levels,
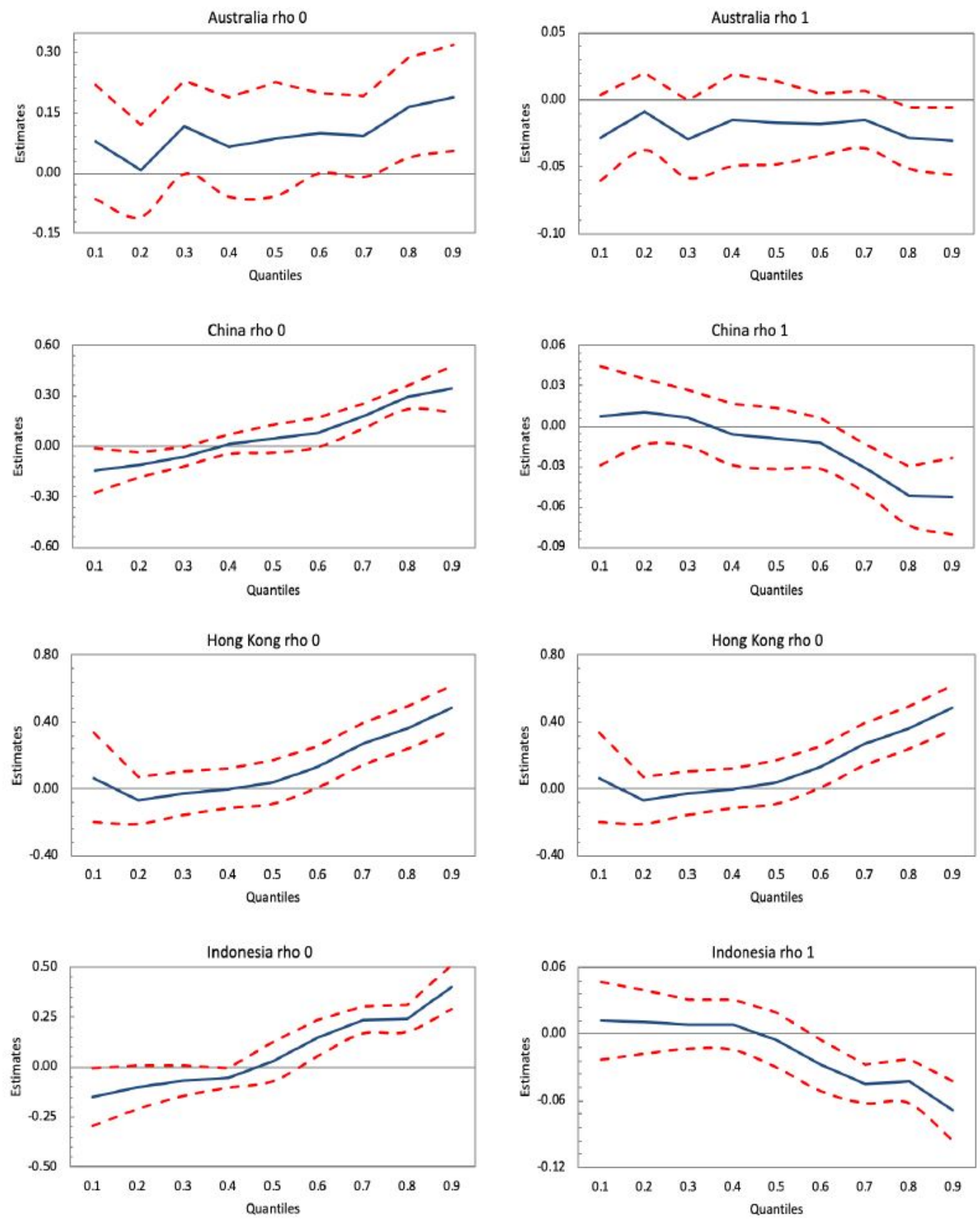
Figure 2. (Continued)
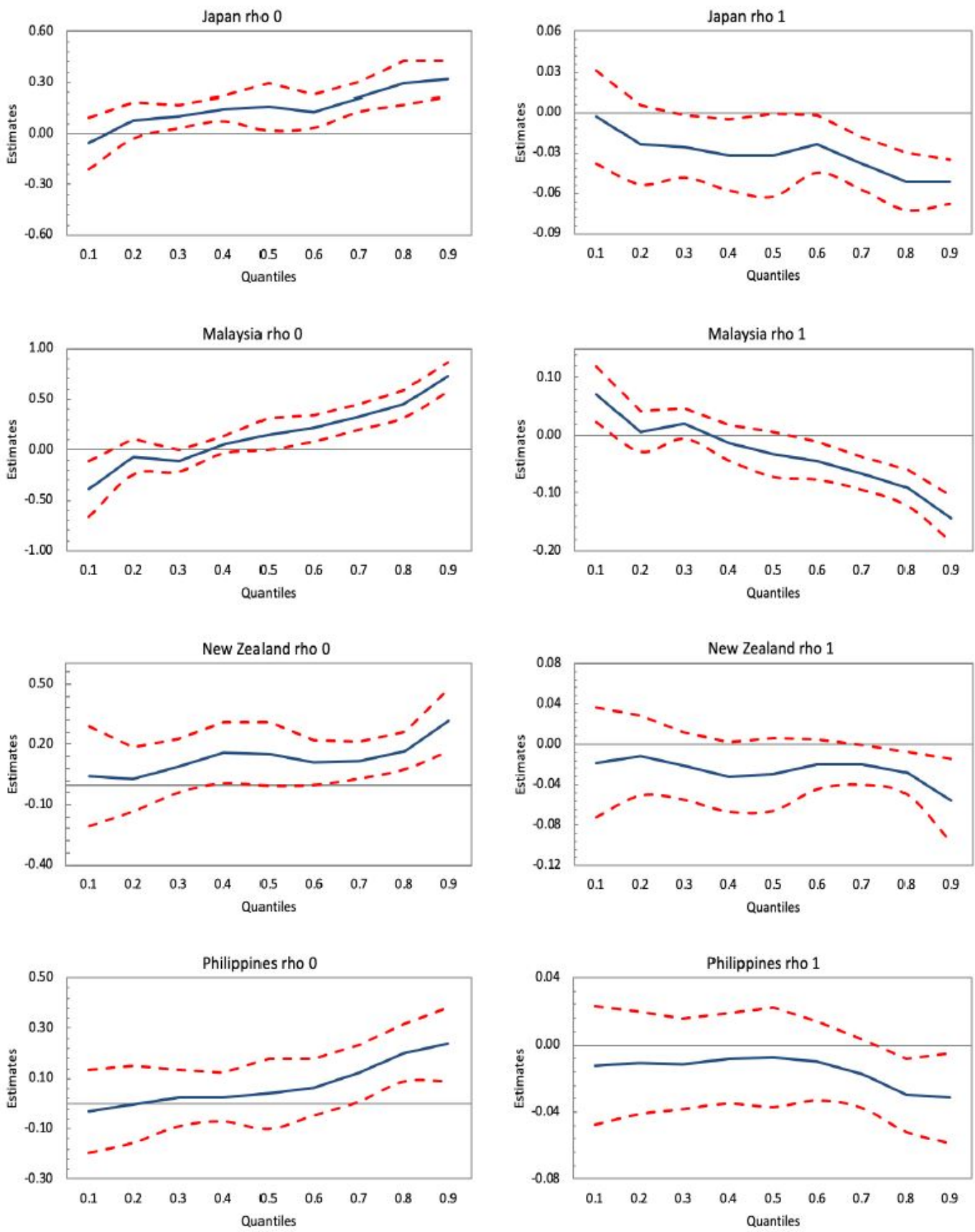
Figure 2. (Continued)
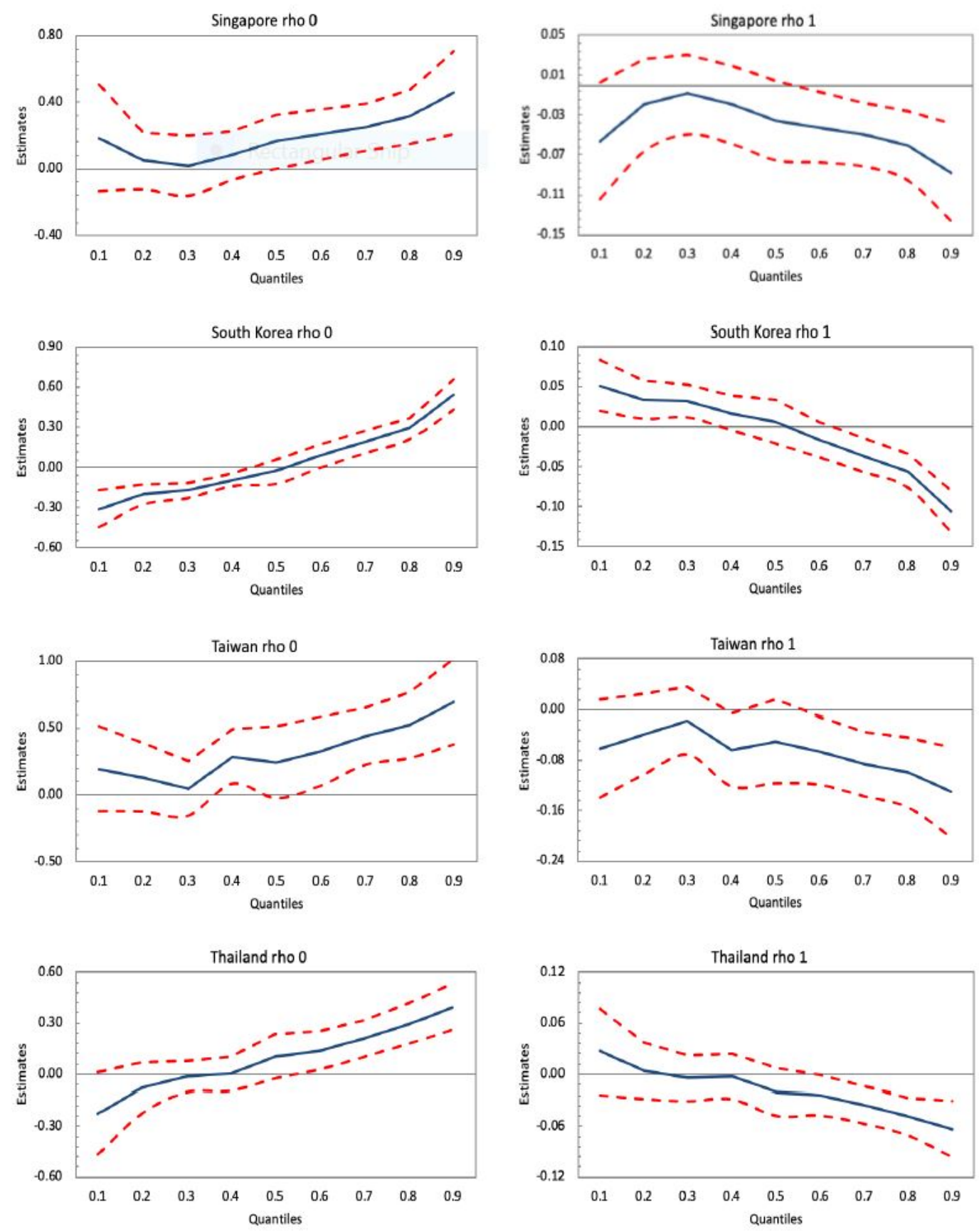